\title{
CONCESSÕES DE RODOVIAS NO BRASIL: FORMAÇÃO DE GRUPOS ECONÔMICOS E CONCENTRAÇÃO DE CAPITAIS
}

\author{
HIGHWAYS CONCESSIONS IN BRAZIL: FORMATION OF ECONOMIC \\ GROUPS AND CAPITAL CONCENTRATION
}

CONCESIONES DE CARRETERAS EN BRASIL: FORMACIÓN DE GRUPOS ECONÓMICOS Y CONCENTRACIÓN DE CAPITALES

\begin{abstract}
Cássio Antunes Oliveira
Doutorado em Geografia pelo Programa de Pós Graduação em Geografia (PPGG) da FCT/UNESP de Presidente Prudente - SP. Faculdade de Ciências e Tecnologia (FCT). Universidade Estadual Paulista (UNESP), Campus de Presidente Prudente (SP). R. Roberto Símonsen, 305 - Centro Educacional, Pres. Prudente - SP, 19060-900.E-mail: cassio.antunes@gmail.com
\end{abstract}

\begin{abstract}
RESUMO
O capitalismo tem como um de seus princípios básicos a concentração de capitais. No setor de infraestrutura rodoviária, isto não é diferente, especialmente após a década de 1990, quando o neoliberalismo penetrou mais profundamente nas decisões políticas no Brasil. Nesse texto são analisadas as trajetórias de cinco grupos econômicos (Arteris, CCR, Ecorodovias, Invepar, Triunfo) e duas grandes empresas (A.B Concessões e Odebrecht TransPort) que atuam em concessões de rodovias no país. Também demonstramos que as concessões de rodovias se constituem em negócios altamente seguro e lucrativo. Os cinco grupos e as duas empresas analisadas concentram 14.192 dos aproximadamente 20 mil quilômetros de rodovias concedidas no Brasil.
\end{abstract}

Palavras-chave: grupos econômicos, concessões de rodovias, Estado, Brasil.

\begin{abstract}
The capitalism has as one of its basic principles the capital concentration. In the infrastructure road sector, it is not different, especially after 1990s, when the neoliberalism affected more deeply the political actions in Brazil. In this paper, we analyze the trajectory of five economic groups (Arteris, CCR, Ecorodovias, Invepar, Triunfo) and two large companies (A.B Concessões e Odebrecht TransPort) that work in road concessions in Brazil. We also demonstrate that road concessions is a profitable business and a secure investment. The five groups and two companies analyzed concenter 14.192 kilometers and almost 20 thousand kilometers of the roads conceived in Brazil.
\end{abstract}

Key words: Economic groups. Road concessions, State, Brazil. 


\section{RESUMEN}

Uno de los principios básicos del capitalismo es la concentración de capitales. En el sector de infraestructura viaria, esto no es diferente, especialmente después de la década de 1990, cuando el neoliberalismo penetró más profundamente en las decisiones políticas en Brasil. En este texto se analiza las trayectorias de cinco grupos económicos (Arteris, CCR, Ecorodovias, Invepar, Triunfo) y dos grandes empresas (A.B Concessões e Odebrecht TransPort) que actúan en concesiones de carreteras en el país. También demostramos que las concesiones de carreteras se constituyen en negocios altamente seguros y lucrativos. Los cinco grupos y las dos empresas analizadas concentran 14.192 de los aproximadamente 20 mil kilómetros de carreteras concedidas en Brasil.

Palabras-clave: grupos económicos, concesiones de carreteras, Estado, Brasil.

\section{INTRODUÇÃO}

Esse texto demonstra como a iniciativa privada se apropria da administração de serviços públicos, por meio de ações promovidas por governos neoliberais, com o objetivo de acumulação rápida de capitais. A acelerada ascensão das empresas pertencentes a grandes grupos ou conglomerados que atuam no segmento de infraestruturas é objeto de análise. Também são feitas considerações sobre a relação entre Estado e concessões e o seu papel de fiscalizador do processo, uma vez que se trata de serviço de interesse público.

Assim, analisamos a trajetória das maiores empresas que atuam no Brasil no negócio das concessões de rodovias considerando seus crescimentos em administração de lotes, nos faturamentos e nas internacionalizações. A investigação foi focada nos maiores grupos que atuam no segmento de infraestruturas de transportes e que se destacam no setor de concessões de rodovias. As principais empresas do setor de concessões no Brasil pertencem aos seguintes grupos: CCR, Invepar, Triunfo, Odebrecht TransPort, Arteris, Ecorodovias e AB Concessões S.A. O grupo Galvão iniciou atividades com administração de rodovias no ano de 2014, porém apesar de ser um grupo de grande porte (possui atuação em diversos outros segmentos, como energia, portos e setor financeiro) não será analisado pelo fato de ainda ter uma pequena participação em concessões de rodovias.

O texto está organizado da seguinte forma: na primeira parte uma caracterização das concessões rodoviárias, problematizadas enquanto novas estratégias para a obtenção de lucros significativos (expropriação, para Harvey [2013], ou mais-valia social, para Kurz [2002]). Há também uma análise sobre as dificuldades que as agências reguladoras encontram para exercerem seu papel na fiscalização das concessões. Na segunda parte, analisamos a alta rentabilidade e segurança proporcionada pela concessão de rodovias aos grupos e 
empresas que atuam no setor. Na segunda parte também analisamos cada um dos cinco grupos econômicos e as duas empresas do setor. Na conclusão, discutimos a problemática da ascensão de grandes grupos no negócio das concessões de rodovias no Brasil.

\section{CONCESSÕES RODOVIÁRIAS COMO NOVOS CAMINHOS PARA LUCRATIVIDADE}

As privatizações e concessões de rodovias significa a saída do Estado na administração e oferta de serviços e de infraestruturas. Assim, obviamente que com a disseminação das ideias neoliberais ampliou-se as áreas e setores em que a iniciativa privada pode atuar e investir. Desta forma, com a ampliação do campo de atuação para os empresários por meio das privatizações de empresas públicas e de concessões de infraestruturas, houve diversos modelos de contratos entre o poder público e a iniciativa privada. Há muitas diferenças entre as exigências nos contratos de concessões de rodovias no que se refere ao valor das tarifas cobradas dos usuários. Nesse sentido, o valor por quilômetro percorrido pode variar significativamente de uma concessão para outra no Brasil. É devido a isso que em algumas unidades da federação as concessões, apesar de cobrar pelo uso das rodovias, ainda permitem que os custos de transportes não sejam aumentados e podem, em alguns casos, até serem menores ${ }^{1}$. Por outro lado, a relação entre Estado e empresários pode comprometer estes custos favorecendo a iniciativa privada, em detrimento da sociedade, como exemplo os contratos firmados entre o Estado de São Paulo e as concessionárias entre os anos de 1998 e 2000, é caracterizado por tarifas extremamente altas. Outro exemplo ocorreu no Rio Grande do Sul, nesses casos significaram até em recusa de instalação de unidades industriais em áreas servidas por essas rodovias devido ao encarecimento dos custos de circulação (SOSSELA, 2012).

Em um exemplo contrário, no Estado da Bahia as concessões foram firmadas sem que os valores das tarifas fossem abusivos, isso favoreceu os agentes econômicos, que tiveram melhoradas suas condições de circulação sem que os custos fossem maiores que os benefícios. Nesse campo de atuação (a economia capitalista) em que se verifica a ausência de solidariedade entre os empresários, as próprias corporações que atuam no setor produtivo também atuam na exploração das rodovias via concessões, como exemplo a Odebrecht, que possui uma empresa especializada nesse tipo de negócio, a Odebrecht TransPort. Estes exemplos mostram que os estudos comparativos dos custos de transportes no Brasil se pautados em análises regionais tendem a trazer resultados mais próximos da realidade. Afirmações sobre consequências das concessões no Brasil podem apresentar resultados muito discrepantes dependendo da escala considerada na análise.

\footnotetext{
Entre contratos de concessão do Estado de São Paulo e os federais há diferenças significativas no que se refere à TIR de lucro para as concessionárias, são $20 \%$ no primeiro caso e $9 \%$ no segundo.
} 
As concessões de rodovias foram também um dos caminhos para investimento de capitais ociosos. Para outras empresas (ligadas ao setor produtivo) que utilizam de forma mais direta as infraestruturas de transportes significou uma possibilidade de obter lucratividade por longo prazo com garantias de segurança (os contratos no Brasil possuem duração média de 30 anos). O perfil da maioria das empresas mais interessadas em concessões de rodovias é o de serem construtoras, como por exemplo, Andrade Gutierrez, Galvão, Triunfo, OAS, Odebrecht e Camargo Corrêa, além de muitas outras com menor participação nas concessões de rodovias, como exemplo, Encalso, Oriente Construções e Delta Construções.

Ao analisar o contexto político-econômico desde o pós-guerra, Harvey (2013), compreende que passado o período de reconstrução dos países que tiveram grandes perdas com a guerra e com a crise do fordismo houve a concentração de capitais que necessitavam serem investidos. Porém, a classe trabalhadora e a orientação keynesiana que influenciou a visão da política, principalmente na Europa, ao longo do período pós-guerra conhecido como dos "30 anos gloriosos" culminaram na década de 1970, com grande concentração de capitais, mas poucas perspectivas para reinvesti-los e certezas de geração de lucros, considerando a taxa de retorno mínima de 3\% (HARVEY, 2011).

Para Harvey (2013) a virada neoliberal estava prestes a ocorrer devido a esse clima para os negócios da década de 1970. Assim,

A virada subsequente para a neoliberalização inclui derrubar toda possível barreira ao desdobramento lucrativo do excedente. Se a classe trabalhadora era forte o bastante para constituir uma barreira à lucratividade, então ela tinha de ser disciplinada, seus salários e benefícios reduzidos, eliminando-se inteiramente sua capacidade para exercer um esmagamento do lucro. Esse objetivo foi alcançado por meio da violência no Chile, pelas falências em Nova York, e politicamente, por Reagan e Thatcher em nome do combate à inflação. Como se tudo isso fosse suficiente, as corporações podiam resolver as coisas por conta própria e se transferir fisicamente para o estrangeiro, para qualquer lugar onde a mão de obra fosse mais barata e mais dócil. Mas, para isso acontecer, todas as barreiras ao comércio exterior precisariam ser derrubadas. As tarifas tinham de ser reduzidas, acordos comerciais antiprotecionistas criados e uma ordem internacional aberta que permitisse o fluxo relativamente livre do capital no mundo todo (grifo nosso, p. 30).

A partir destas reflexões de Harvey (2013), as concessões podem ser compreendidas também como reduções das barreiras ao comércio exterior, uma vez que, no caso do Brasil, promovem vias de penetração para os mercados internos com qualidade de fluidez e de segurança. Assim, as concessões possuem diversas facetas, como por exemplo, novos meios para lucratividade e redução das barreiras para a atuação das empresas e corporações. 
Nas últimas três décadas foram sendo gestados e organizados os mecanismos de abertura de um novo campo de expropriação de recursos da sociedade, que culminou nos processos denominados de privatizações e de concessões. No caso das concessões de rodovias foi ao longo dos anos, no Brasil, se constituindo uma especialização das empresas do setor que tiveram seus capitais multiplicados em poucos anos. Junto a esse processo houve também a criação de negócios paralelos associados à utilização das infraestruturas. Para exemplificar podem-se citar os sistemas eletrônicos de cobrança, como é o caso dos sistemas Sem Parar², Via Fácil, Conect Car, Dbtrans e Move Mais. Não por acaso os principais grupos empresariais que possuem concessionárias também são acionistas dessas empresas de cobrança eletrônica. Essas formas de cobrança em praças de pedágio também passaram a ser utilizadas em diversos estacionamentos, como por exemplo, em shopping centers.

Há um desdobramento dos negócios associados às concessões. Essa cadeia de oportunidades de atuação dessas empresas do setor de infraestruturas e serviços de mobilidade tem como articulador e parceiro o Estado. Na verdade, o Estado prepara todo o "campo de atuação" oferecendo segurança e o que chamamos de base, uma vez que recupera todas as infraestruturas antes de oferecer nos leilões, ou caso não faça a recuperação. O Estado continua atuando para a oferta e manutenção da infraestrutura rodoviária por meio do aporte de capitais via banco de investimento público, o Banco Nacional de Desenvolvimento Econômico e Social (BNDES), mesmo depois de concedidas, ficando a cargo das concessionárias apenas a gestão. Para exemplificar, um trecho de um texto sobre as concessões retirado do domínio eletrônico da Logística Brasil (que é do governo federal) mostra a contrapartida do Estado em relação aos custos financeiros. De acordo com o site "o modelo de concessão prevê a execução de obras de duplicação que deverão ser concluídas durante os primeiros cinco anos de contrato. Os bancos públicos brasileiros poderão financiar até 70\% do investimento a uma taxa de juros de até 2,0\% a.a. mais a TJLP”" (Grifo nosso) (LOGÍSTICA BRASIL, 2015).

A figura 1 mostra um exemplo de como, mesmo após a infraestrutura estar concedida, o Estado continua fazendo investimentos, trata-se de uma placa fixada às margens da rodovia Raposo Tavares (SP 270) no Estado de São Paulo que foi concedida em 2008 para a concessionária Cart, que pertence ao grupo Invepar. Na placa há a informação do capital investido pelo Estado de São Paulo para a construção de um dispositivo, no valor

\footnotetext{
Sem Parar e Via Fácil são sistemas de pagamento eletrônico para usuários de rodovias concedidas e de estacionamentos conveniados. Com o dispositivo de identificação (TAG) instalado no veículo a cancela dos pedágios identificam a aproximação do veículo e assim o usuário não precisa parar nas cabines de cobrança. A cada 30 dias é enviada uma fatura para o usuário ou é realizado um débito na sua conta bancária. "Hoje, o sistema é utilizado por 3 milhões de clientes e está presente em 94\% das rodovias pedagiadas do País e em aproximadamente 100 estacionamentos de sete Estados” (GRUPO CCR, 2014).

Taxa de Juros de Longo Prazo.
} 
de $\mathrm{R} \$ 2.128 .055,36$. Devido ao fato de o Estado realizar os investimentos e até $70 \%$ dos empréstimos, há pessoas que atribuem, de forma irônica, às concessionárias de rodovias a tarefa de "podadoras de gramas e mato" das margens das rodovias".

O BNDES faz a captação dos recursos, seja via reembolsos, seja via FAT e FGTS e oferece às empresas concessionárias. O maior montante investido pelas concessionárias nas concessões é via BNDES. É neste sentido que atribuímos como papel destas empresas o de gestão. As agências reguladoras (federal, na figura da ANTT ou estaduais) têm dificuldades para fiscalizar todas as concessões sob suas responsabilidades, o que pode acarretar na não inversão do total de recursos tomados de empréstimo. A Agência Estadual de Regulação dos Serviços Públicos Delegados do Rio Grande do Sul (AGERGS) apresentou suas dificuldades na CPI dos pedágios do Estado do Rio Grande do Sul como, por exemplo, o número de funcionários ser reduzido, o que torna muito complicada a fiscalização (SOSSELA, 2012).

A Agência Nacional de Transportes Terrestres (ANTT) reclamou na Comissão de Infraestrutura realizada no senado federal que necessita de mais funcionários para fiscalizar as concessões. Em 2013 foram concedidos mais de 4.000 quilômetros e a ANTT não tinha aumentado seu quadro de funcionários até a data do referido evento (PEDRUZZI e MELO, 2014). Já no Estado de São Paulo a CPI dos pedágios mostrou que a Agência Estadual de Regulação dos Serviços Públicos Delegados de Transporte do Estado de São Paulo (ARTESP) tem muitas dificuldades para executar a fiscalização.

Figura 1: Placa às margens da rodovia Raposo Tavares (SP 270) com os valores investidos pelo Estado de São Paulo na implantação de um dispositivo.

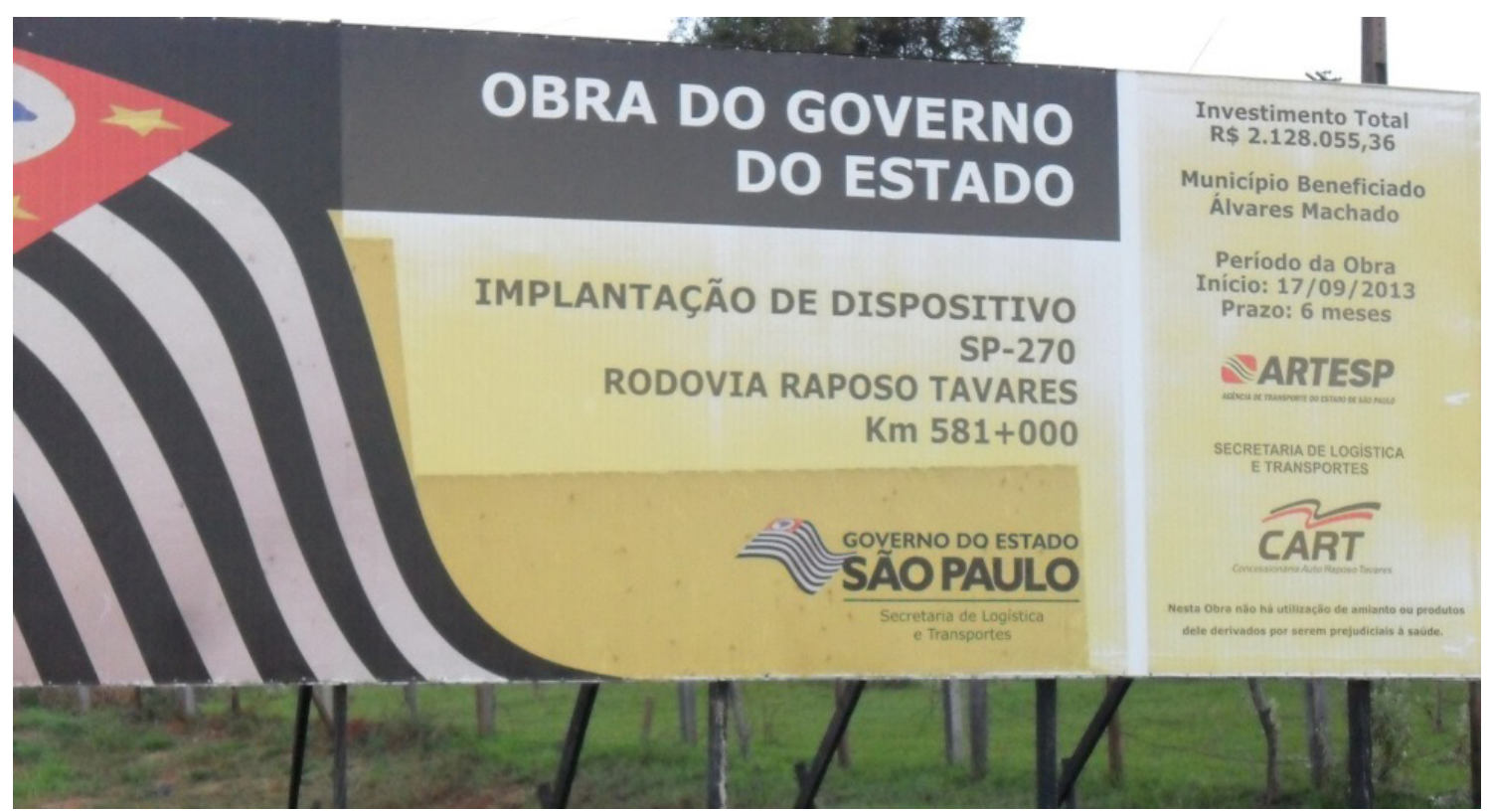

Fonte: Nelio Rosa, 2014.

Esta afirmação foi feita em uma entrevista com integrantes do Fórum Nacional dos Transportes (FNT) na cidade de Curitiba (PR). 
Para ficar com três exemplos: no primeiro, ao ser questionada se as concessionárias estavam executando obras nas rodovias vicinais que ficaram responsáveis (etapa das concessões de 2008), a empresa não apresentou documentação que comprovasse; no segundo, a ARTESP compromete um terço do seu orçamento com a contratação de auditorias particulares; no terceiro, passados 17 anos que iniciaram as primeiras concessões no estado, a ARTESP ainda não conseguiu implantar um sistema que faça a contagem dos fluxos de veículos nas praças de pedágio, ficando, assim, refém das informações repassadas pelas concessionárias 5 . A Lei Federal 8.987/95 garante o acesso aos dados das concessões para fins de fiscalização. Segundo seu artigo 30 "no exercício da fiscalização, o poder concedente terá acesso aos dados relativos à administração, contabilidade, recursos técnicos, econômicos e financeiros da concessionária”. E no parágrafo único garante que,

A fiscalização do serviço será feita por intermédio de órgão técnico do poder concedente ou por entidade com ele conveniada, e, periodicamente, conforme previsto em norma regulamentar, por comissão composta de representantes do poder concedente, da concessionária e dos usuários (Lei Federal 8.987/95).

Aumentar a quilometragem de rodovias concedidas requer que o Estado tenha capacidades de fiscalizá-las, ou seja, os gastos também aumentam, uma vez que é necessário ter funcionários próprios nas agências de fiscalização, como é o caso da ANTT. O papel do Estado no discurso neoliberal dificilmente é percebido como sendo o representante dos interesses da sociedade, uma vez que a intencionalidade é apresentar o mercado como capacitado e eficiente. Nesse sentido, quanto menos exigências às concessionárias, mais limitadas ficam as concessões como alternativa para resolver o problema da oferta e expansão das infraestruturas de transportes. É necessário considerar que os trechos que mais eram atraentes para concessão já foram concedidos. A concessão não é uma solução para os problemas de financiamento da construção e manutenção das infraestruturas de transportes rodoviários no Brasil, é apenas uma medida paliativa. Elas não solucionam os problemas de oferta e financiamento das infraestruturas porque possuem viabilidade para as áreas que já são dinâmicas, pois o Volume Diário Médio (VDM) de veículos é o principal elemento na negociação dos contratos de longo prazo. Nesse sentido, trechos com baixo VDM não justificam do ponto de vista dos fluxos a concessão. A questão que fica é, como o Estado resolverá o problema de financiamento da construção e manutenção das infraestruturas das rodovias que se localizam em áreas e regiões cujo VDM não é

\footnotetext{
"Mesmo já tendo transcorrido 16 anos do início das privatizações das rodovias paulistas e o mundo registrado importantes avanços tecnológicos na área de informática, registro de imagens e monitoramento remoto, o sistema responsável por aferir com precisão o movimento de veículos, gerador de toda riqueza proporcionada pelos pedágios paulista, ainda é frágil e grande parte do processo está sob o controle e intervenção direta das Concessionárias, possibilitando fraudes" (MENTOR e BITTENCOURT, 2014, p. 68).
} 
permitem viabilidade econômica para empresas concessionárias? Quais as consequências das concessões para a redução das disparidades regionais?

Feitas essas considerações sobre as concessões rodoviárias no Brasil analisaremos em seguida como esse setor contribuiu para a constituição de grupos econômicos de forma rápida.

\section{CONCESSÕES DE RODOVIAS NO BRASIL: NEGÓCIO LUCRATIVO E SEGURO}

As concessões de rodovias podem ser compreendidas também como um negócio. No Brasil o negócio das concessões rodoviárias vem crescendo expressivamente desde 1996, ano em que ocorre definitivamente o início desta forma de administração do patrimônio público e de parte da infraestrutura rodoviária. Elaine Behring (2008), ao fazer uma análise do contexto de emergência do neoliberalismo também considera que houve uma degradação induzida de alguns serviços públicos que levaram a uma legitimação das privatizações. Foi esse o caminho para a mercantilização e a transformação de políticas sociais em negócios (MANDEL, 1982 apud BEHRING, 2008) $)^{6}$.

No caso das concessões rodoviárias, para exemplificar, em 1996 o total de 19.563,940 veículos pagaram pedágio, em 1998 esse número sobe para 230.181,786, e em 2012 foram 1.585.898.249. Conforme se pode verificar na figura 2 .

\footnotetext{
As concessões de rodovias também podem ser compreendidas como uma forma de garantir por prazos longos, determinados trechos que interessam mais à iniciativa privada. Os prazos longos, que giram em torno de 20 a 30 anos, são uma forma de tirar a desconfiança em governos que poderiam administrar mal essas rodovias. O Estado nesse caso "[...] não prescinde de seu pressuposto geral [...] que lhe assegura as condições de produção e reprodução. Hoje, cumprir com esse papel é facilitar o fluxo global de mercadorias e dinheiro, por meio, como já foi sinalizado, da desregulamentação de direitos sociais, de garantias fiscais ao capital, da 'vista grossa' para a fuga fiscal, da política de privatização, dentre inúmeras possibilidades que pragmaticamente viabilizem a realização dos superlucros e da acumulação” (BEHRING, 2008, p. 64).
} 
Figura 2: Brasil: histórico de veículos que pagaram pedágio e isentos no período 1996-2012.

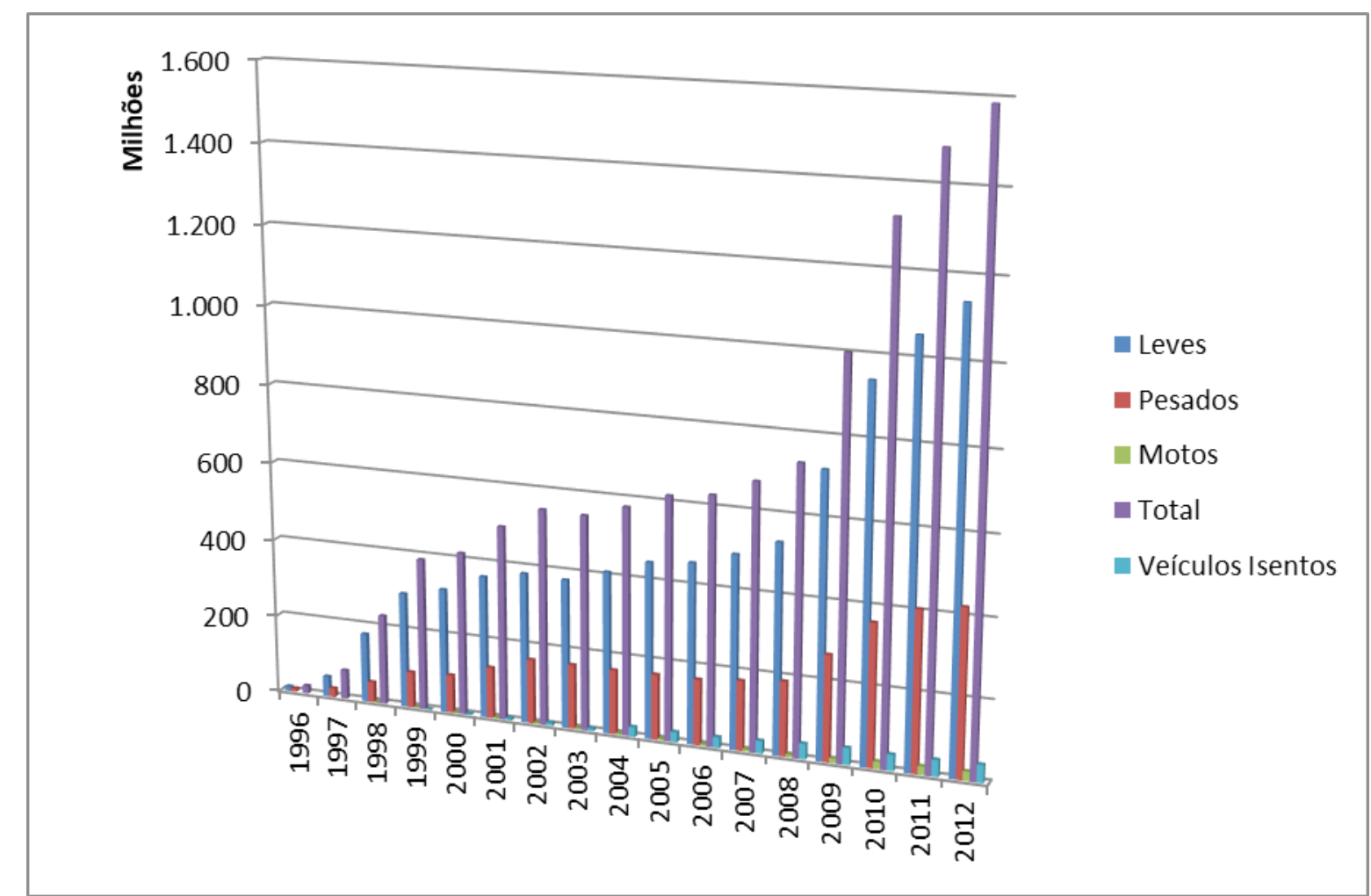

Fonte: $A B C R, 2013$.

Há algumas diferenças entre o negócio das concessões no Brasil em relação a outros países, como a França, por exemplo. Na França há uma lei (Lei n. 89-465 de 10 de julho de 1989, art. 10) que estabelece que a participação estrangeira nas privatizações não deve ultrapassar 20\% (DERANI, 2002). No Brasil a lei equipara pessoas estrangeiras aos cidadãos de nacionalidade brasileira e resguarda as leis supervenientes ou a "manifestação expressa do poder executivo" a possibilidade de restrição no artigo 12. Porém, isso de

[...] fato jamais ocorreu de modo efetivo. Inclusive, no que tange as instituições financeiras, não há qualquer limitação da participação do capital estrangeiro, que hoje já representa mais de $43 \%$ do capital das instituições financeiras no Brasil. Sem considerar outros efeitos nefastos, esta internacionalização do patrimônio público provoca recordes de remessa de lucro, que não conta com nenhuma limitação (DERANI, 2002, p. 131).

A segunda etapa de concessões do Estado de São Paulo e a Segunda Etapa das Concessões de Rodovias Federais tiveram como vencedoras dos contratos em sua maioria empresas estrangeiras, aumentando a participação do capital estrangeiro no negócio das concessões rodoviárias. Empresas como a Arteris de capital espanhol foi uma das que ampliaram os trechos rodoviários sob sua administração. 
Essa tendência de participação estrangeira perdeu força com os contratos de concessões federais do governo Dilma Rousseff, a maioria dos lotes teve como vencedoras empresas pertencentes a grupos nacionais, como é o caso da Triunfo, Odebrecht Transport e CCR. A CCR, ao todo administra 3.284 quilômetros nos Estados de São Paulo, Rio de Janeiro, Paraná e Mato Grosso do Sul.

Esses exemplos mostram que a concessão rodoviária é um negócio atraente para as empresas que buscavam opções para investir seus capitais com possibilidades de retorno positivo e com segurança contra perdas. No Brasil, as concessões são negócios seguros pelo fato de ser o modal de transporte mais utilizado para o transporte de cargas e quase o único para o transporte de passageiros, salvo pouquíssimas exceções de transporte em trilhos entre cidades de algumas regiões metropolitanas (como exemplo na Região Metropolitana de São Paulo) e poucas exceções de uso de hidrovias e cabotagem. Desta forma, mesmo em períodos de crise e recessão, pelo fato de também não ter a obrigação de rotas alternativas para as concedidas, o VDM nas rodovias concedidas não sofre redução significativa. Ao contrário ocorre na Espanha e em Portugal, uma vez que com a crise aprofundada a partir de 2007 houve redução drástica do VDM em algumas rodovias.

Serviços públicos, pelo seu princípio não devem ser transformados em negócios, pois conforme afirma Derani (2002),

De um modo geral, os objetivos que caracterizam o serviço público em sentido estrito são: continuidade do serviço efetivo no tempo, universalidade geográfica da prestação (atender a todos em qualquer parte da sociedade); equidade no tratamento dos usuários, compatível com as imposições financeiras, econômicas e sociais (p. 67).

Assim, pode se observar que os objetivos do serviço público e os da iniciativa privada não são convergentes para empreendimentos que atendam de modo uniforme todo o território. Apenas determinadas fatias de serviço público interessam ao mercado. As privatizações, concessões e Parcerias Público Privadas (PPP) geralmente administram serviços que são taxados de serem oferecidos de uma forma descompromissada pelo Estado em relação à qualidade do serviço de interesse público prestado para a população e, se por um lado livra o Estado de oferecer tal serviço, por outro lado, não o livra de fiscalizá-lo ${ }^{7}$, embora sendo autarquias, as agências reguladoras são extensões do Estado. Esta desconfiança reside na tendência a considerar que o serviço de interesse público é prestado com maior qualidade

É válido deixar registrado que para alguns setores privatizados ou concedidos no Brasil primeiro houve a privatização e posteriormente a criação de agências reguladoras ou fiscalizadoras (ARAÚJO, 2005). Assim, é possível perceber que essas iniciativas foram feitas às pressas e sem que o Estado brasileiro tivesse conhecimento de como implementar e seguir com essas novas formas de governabilidade. 
nos setores privatizados ou concedidos, no entanto, isso pode ocorrer também de forma inversa. No Estado do Mato Grosso a concessionária Morro da Mesa foi acionada mais de uma vez na justiça pela Fundação de Proteção e Defesa do Consumidor (PROCON - MT) acusada de oferecer serviços aquém dos previstos em contrato.

No caso de rodovias que cobram pedágio no Brasil, as com administração privada apresentam melhores condições de uso e de serviços aos usuários, conforme resultado de pesquisa realizada pela Confederação Nacional de Transporte (CNT, 2014, 2015), porém há razões históricas que explicam esse fato. No Estado de São Paulo os melhores trechos rodoviários com existência de pista dupla e significativo VDM foram recuperados e depois concedidos. Desta forma, a iniciativa privada desde que passou a administrar esses trechos (classificados como os melhores do país) tem apenas conservado a qualidade das rodovias (pavimento e sinalização) e realizado intervenções como construção de passarelas, viadutos e retornos. Devido as seguintes razões que os melhores trechos rodoviários do país são concedidos; investimentos feitos por sucessivos governos do Estado de São Paulo na construção e manutenção dessas rodovias, que foram iniciados desde a década de 1970 e continuaram nos planos dos governos das décadas de 1980 e 1990 (NEGRI, 1996). Em suma, não se trata de mérito somente da iniciativa privada, mas de investimentos do Estado ao longo de mais de três décadas.

No caso de outros tipos de serviços de interesse público privados como os de telecomunicações, é possível afirmar que, principalmente, em relação a telefonia móvel no Brasil os serviços prestados pelas empresas privadas deixam a desejar no que se refere a qualidade. Como exemplo pode-se citar um fato ocorrido em 2012 no qual três das quatro principais operadoras foram proibidas pela Agência Nacional de Telecomunicações (ANATEL) de vender novas linhas de celular em vários estados em razão das péssimas condições de uso das linhas já existentes (BRODBECK, 2012).

\section{OS SETE GRANDES GRUPOS DO SETOR DE CONCESSÕES DE RODOVIAS QUE ATUAM NO BRASIL}

Antes de adentrar na análise e descrição dos grupos e conglomerados é necessário esclarecer como compreendemos estas duas noções. De acordo com Sposito e Santos (2012, p. 58),

[...] grupos econômicos são definidos como formas organizacionais caracterizadas por um conjunto de firmas, de atuação em diferentes ramos econômicos que podem ou não ser relacionadas dependendo das capacidades tecnológicas/ gerenciais e das economias de escala e escopo potenciais, mantidas sob o controle comum de uma ou mais famílias ou grupo de investidores (pessoas jurídicas ou instituições) que decidem, pelo contexto institucional e estratégias de crescimento, abrir ou manter fechado o capital das firmas ou do próprio grupo.

8 Ver < http://www.gazetadopovo.com.br/economia/anatel-proibe-tim-oi-e-claro-de-venderem-linhas-e-pacotes-de-dados2a4d52uokxsw6s3j618ri98we>. Acesso em 13 Jan. 2016. 
Os grupos que atuam no setor de concessões de rodovias no Brasil podem ser assim denominados conforme a compreensão de Sposito e Santos (2012) para grupos econômicos. Conforme destacado por Sposito e Santos (2012) a origem dos grupos podem ter diversas causas. O principal a reter é que são consequência das relações capitalistas de produção e são um resultado da concentração e centralização de capitais. Ainda segundo os referidos autores, baseados em Benko (1996), os grupos estabelecem relações com outras empresas além das pertencentes ao próprio grupo, isto contribui para compreender uma prática dos últimos anos que constatamos na nossa análise dos grupos ligados às concessões de rodovias, que é a participação dos fundos de pensão nestes grupos ${ }^{9}$.

Há cinco grandes grupos e duas grandes empresas que atuam no setor das concessões no Brasil, os quais são: Arteris, CCR Concessões, Invepar, Odebrecht TransPort, EcoRodovias, Triunfo e AB Concessões S.A. Alguns desses grupos possuem capital aberto na BMF/ Bovespa (Arteris, CCR, EcoRodovias, Invepar e Triunfo) o que mostra que esse negócio é bastante atraente ao grande capital. A AB Concessões S.A. afirmou que pretende abrir seu capital em 2016 (PUPO, 2013). Outra evidência do sucesso dessa modalidade de negócio é o rápido crescimento destes grupos em prazos relativamente curtos, que giram em torno de 5 a 18 anos. Faremos uma análise de cada um destes grupos e empresas considerando a participação no setor de concessões de rodovias no Brasil e no exterior, a composição acionária dessas empresas e os balanços financeiros trimestrais de 2015.

Em 2015 entrou em vigor da Lei dos Caminhoneiros (vigente desde abril de 2015) ${ }^{10}$, que proíbe a cobrança de pedágio dos eixos suspensos dos caminhões. Esta nova Lei foi responsável pela queda da receita dos sete grandes grupos em torno de $5 \%$. No entanto com os reajustes nos valores das taxas de pedágio autorizados nas concessões federais e estaduais essa perda por parte das concessionárias foi revertida, inclusive algumas já registram aumento nas receitas com pedágio, como é o caso da Arteris que registrou aumento de 1,1\% no segundo trimestre de 2015.

As tabelas 1 e 2 mostram os acionistas das concessionárias de rodovias no Brasil. A análise das tabelas evidencia que uma minoria das concessionárias tem controladores independentes, ou seja, esse é um setor que tende a concentrar capital nas mãos de corporações e grandes grupos. A participação estrangeira, como mencionado, estagnou com o fortalecimento de grandes grupos nacionais que inclusive expandiram suas atividades em alguns países da

\footnotetext{
9 "A definição ajuda a compreender a multiplicação de acordos e parcerias, sobretudo nos últimos anos, como decorrência do avanço das práticas e estratégias financeiras dentro dos grupos, bem como a penetração dos fundos mútuos de investimentos e fundos de pensão no seio dos grupos e empresas, estabelecendo-se como principais acionistas e impondo a lógica de valorização do capital financeiro" (SPOSITO e SANTOS, 2012, p. 58).

10 Lei 13.103/2015 é conhecida como a lei dos caminhoneiros, mas só está vigente nas rodovias federais, nas rodovias estaduais dos Estados de São Paulo e do Paraná a cobrança dos eixos suspensos continua ocorrendo.
} 
América Latina, como é o caso da Invepar. Há também a participação de grupos estrangeiros em empresas com maioria de controladores brasileiros entre os acionistas.

Tabela 1: Grupos controladores de concessionárias de rodovias no Brasil - 2015.

\begin{tabular}{|c|c|c|c|c|c|c|}
\hline $\begin{array}{c}\text { Grupos } \\
\text { controladores }\end{array}$ & $\begin{array}{l}\text { Part. } \\
\%\end{array}$ & Concessionárias & Prog. & UF & $\begin{array}{l}\text { Ext. } \\
\text { Km. }\end{array}$ & Rodovias \\
\hline AB Concessões & $100 \%$ & Colinas & SP & SP & 307 & $\begin{array}{l}\text { SP } 075 / ; 127 ; 280 \\
300 ; \text { SP } 102 / 300\end{array}$ \\
\hline AB Concessões & $100 \%$ & $\begin{array}{l}\text { Nascentes das } \\
\text { Gerais }\end{array}$ & MG & MG & 371 & $\begin{array}{c}\text { MG 050; BR 491; } \\
\text { BR 265 }\end{array}$ \\
\hline AB Concessões & $50 \%$ & Rodovias do & & & & SP 300; SP 113; \\
\hline Ascendi & $50 \%$ & Tietê & SP & $\mathrm{SP}$ & 406 & $\begin{array}{c}\text { SP 101; SP 209; } \\
\text { SP } 308\end{array}$ \\
\hline AB Concessões & $100 \%$ & Triângulo do Sol & SP & SP & 442 & $\begin{array}{c}\text { SP 310; SP 326; } \\
\text { SP } 333\end{array}$ \\
\hline & & Total Km & & & 1.526 & \\
\hline \multirow{10}{*}{ Arteris } & $100 \%$ & $\begin{array}{c}\text { Autopista Fernão } \\
\text { Dias }\end{array}$ & Fed. & MG/SP & 562 & BR 381 \\
\hline & $100 \%$ & $\begin{array}{l}\text { Autopista } \\
\text { Fluminense }\end{array}$ & Fed. & RJ & 320 & BR 101 \\
\hline & $100 \%$ & $\begin{array}{c}\text { Autopista Litoral } \\
\text { Sul }\end{array}$ & Fed. & $\mathrm{PR} / \mathrm{SC}$ & 382 & $\begin{array}{c}\text { BR 116; BR 376; } \\
\text { BR 101/SC }\end{array}$ \\
\hline & $100 \%$ & $\begin{array}{c}\text { Autopista } \\
\text { Planalto Sul }\end{array}$ & Fed. & $\mathrm{PR} / \mathrm{SC}$ & 413 & BR 116 \\
\hline & $100 \%$ & $\begin{array}{c}\text { Autopista Régis } \\
\text { Bittencourt }\end{array}$ & Fed. & & 402 & BR 116 \\
\hline & $100 \%$ & Autovias & SP & SP & 317 & $\begin{array}{c}\text { SP } 255 ; 318 ; 330 ; \\
334 ; 345\end{array}$ \\
\hline & $100 \%$ & Centrovias & SP & SP & 218 & SP 310; SP 225 \\
\hline & $100 \%$ & Intervias & SP & SP & 376 & $\begin{array}{c}\text { SP 147; 191; 215; } \\
\text { 330; 352; SP 157; } \\
\quad 340 ; 165 ; 330\end{array}$ \\
\hline & $100 \%$ & Vianorte & SP & $\mathrm{SP}$ & 262 & $\begin{array}{l}\text { SP 330; SP 322; } \\
\text { SP 328; SP } 325\end{array}$ \\
\hline & & Total Km & & & 3.252 & \\
\hline \multirow{7}{*}{ CCR } & $100 \%$ & Nova Dutra & Fed. & $\mathrm{RJ} / \mathrm{SP}$ & 402 & BR 116/SP/RJ \\
\hline & $100 \%$ & Ponte & Fed. & $\mathrm{RJ}$ & 23 & BR 101 \\
\hline & $100 \%$ & Autoban & SP & SP & 317 & $\begin{array}{l}\text { SP 348; SP 330; } \\
300 ; \text { SP 132; } 330\end{array}$ \\
\hline & $100 \%$ & SPVias & SP & SP & 519 & $\begin{array}{c}\text { SP 280; 255; } 127 ; \\
270 ; 258\end{array}$ \\
\hline & $100 \%$ & Via Oeste & SP & SP & 169 & $\begin{array}{c}\text { SP 280; } \\
270 ; 075 ; 091\end{array}$ \\
\hline & $100 \%$ & Via Lagos & $\mathrm{RJ}$ & RJ & 57 & RJ 124 \\
\hline & $100 \%$ & MS Via & Fed. & MS & 847 & $\begin{array}{c}\text { BR 163/MS } \\
\text { Div. MS/MT até } \\
\text { Div. MS/PR }\end{array}$ \\
\hline
\end{tabular}




\begin{tabular}{|c|c|c|c|c|c|c|}
\hline $\begin{array}{c}\text { Grupos } \\
\text { controladores }\end{array}$ & $\begin{array}{l}\text { Part. } \\
\%\end{array}$ & Concessionárias & Prog. & UF & $\begin{array}{l}\text { Ext. } \\
\text { Km. }\end{array}$ & Rodovias \\
\hline CCR & $85,92 \%$ & \multirow{3}{*}{ Rodonorte } & \multirow{3}{*}{ PR } & \multirow{3}{*}{$\mathrm{PR}$} & \multirow{3}{*}{568} & BR 277; BR 376; \\
\hline J. Malucelli & $6 \%$ & & & & & BR 373; \\
\hline Cepar-Cesbe & $8,08 \%$ & & & & & \\
\hline CCR & $95 \%$ & \multirow{2}{*}{ Rodoanel Oeste } & \multirow{2}{*}{ SP } & \multirow{2}{*}{ SP } & \multirow{2}{*}{30} & \multirow{2}{*}{ SP 021} \\
\hline \multirow[t]{2}{*}{ Encalso } & $5 \%$ & & & & & \\
\hline & & Total Km & & & 2.932 & \\
\hline ECORODOVIAS & $90 \%$ & \multirow[b]{2}{*}{ Ecosul } & \multirow[b]{2}{*}{ Fed. } & \multirow[b]{2}{*}{ RS } & \multirow[b]{2}{*}{457} & \\
\hline $\begin{array}{c}\text { Grant Concessões } \\
\text { Partic. }\end{array}$ & $10 \%$ & & & & & RS; BR 392 \\
\hline \multirow{4}{*}{ ECORODOVIAS } & $100 \%$ & Ecovias & SP & & 177 & $\begin{array}{c}\text { SP 150; 160; } \\
041 ; 059 ; \\
055 ; 248 ; 055\end{array}$ \\
\hline & $100 \%$ & Ecopistas & SP & & 135 & $\begin{array}{c}\text { SP 070; 019; } \\
\text { 099; SP 179; } \\
\text { 060; 035; } 056 \\
\end{array}$ \\
\hline & $100 \%$ & Ecovia & PR & & 175 & $\begin{array}{c}\text { BR 277; PR 508; } \\
\text { 407; 804; } \\
408 ; 411\end{array}$ \\
\hline & $100 \%$ & Ecocataratas & PR & & 459 & $\begin{array}{c}\text { BR 277;PR 874; } \\
\text { 590; 180; } 474\end{array}$ \\
\hline ECORODOVIAS & $58 \%$ & \multirow{3}{*}{ Eco 101} & \multirow{3}{*}{ Fed. } & \multirow{3}{*}{ ES } & \multirow{3}{*}{476} & \multirow{3}{*}{ BR 101; ES } \\
\hline $\begin{array}{c}\text { Grant } \\
\text { Concessões Partic. }\end{array}$ & $14,50 \%$ & & & & & \\
\hline \multirow[t]{2}{*}{$\begin{array}{c}\text { Centauros } \\
\text { Participações }\end{array}$} & $27,50 \%$ & & & & & \\
\hline & & Total Km & & & 1.879 & \\
\hline INVEPAR & $100 \%$ & CART & SP & SP & 444 & $\begin{array}{l}\text { SP 225; SP 327; } \\
\text { SP } 270\end{array}$ \\
\hline INVEPAR & $100 \%$ & LAMSA & RJ & RJ & 17 & Linha Amarela \\
\hline INVEPAR & $91,5 \%$ & \multirow[b]{2}{*}{ CLN } & \multirow[b]{2}{*}{ RJ } & \multirow[b]{2}{*}{ BA } & \multirow[b]{2}{*}{217} & \multirow[b]{2}{*}{ BA 099} \\
\hline $\begin{array}{l}\text { Odebrecht } \\
\text { Transport }\end{array}$ & $8,50 \%$ & & & & & \\
\hline INVEPAR & $29,91 \%$ & \multirow{5}{*}{ CRT } & \multirow{5}{*}{ Fed. } & \multirow{5}{*}{ RJ } & \multirow{5}{*}{143} & \multirow{5}{*}{ BR 116 RJ } \\
\hline $\begin{array}{c}\text { Carioca Christian } \\
\text { Nielsen }\end{array}$ & $21,35 \%$ & & & & & \\
\hline Queiroz Galvão & $21,35 \%$ & & & & & \\
\hline Strata & $16,62 \%$ & & & & & \\
\hline \multirow[t]{2}{*}{ Diversos } & $15,77 \%$ & & & & & \\
\hline & & Total Km & & & 821 & \\
\hline $\begin{array}{l}\text { Odebrecht } \\
\text { Transport }\end{array}$ & $100 \%$ & $\begin{array}{l}\text { Rota das } \\
\text { Bandeiras }\end{array}$ & SP & SP & 297 & $\begin{array}{c}\text { SP 063; 065; 083; } \\
\text { 332; 360; SP 122; } \\
065 ; 067 ; 360 ; \\
114 ; 332\end{array}$ \\
\hline
\end{tabular}




\begin{tabular}{|c|c|c|c|c|c|c|}
\hline $\begin{array}{c}\text { Grupos } \\
\text { controladores }\end{array}$ & $\begin{array}{l}\text { Part. } \\
\%\end{array}$ & Concessionárias & Prog. & UF & $\begin{array}{l}\text { Ext. } \\
\text { Km. }\end{array}$ & Rodovias \\
\hline $\begin{array}{c}\text { Odebrecht } \\
\text { Transport }\end{array}$ & $75 \%$ & \multirow{2}{*}{$\begin{array}{l}\text { Rota dos } \\
\text { Coqueiros }\end{array}$} & \multirow[t]{2}{*}{ PE } & \multirow[t]{2}{*}{ PE } & \multirow[t]{2}{*}{7} & \multirow[t]{2}{*}{ PE 024} \\
\hline Cornélio Brennand & $25 \%$ & & & & & \\
\hline $\begin{array}{c}\text { Odebrecht } \\
\text { Transport }\end{array}$ & $100 \%$ & Rota do Oeste & Fed. & MT & 851 & BR 163 \\
\hline $\begin{array}{l}\text { Odebrecht } \\
\text { Transport }\end{array}$ & $70 \%$ & \multirow{4}{*}{$\begin{array}{l}\text { Rota das } \\
\text { Fronteiras }\end{array}$} & \multirow{4}{*}{$\begin{array}{l}\text { PR - } \\
\text { PPP }\end{array}$} & \multirow{4}{*}{ PR } & \multirow{4}{*}{220} & \multirow{4}{*}{$\begin{array}{c}\text { PR } 323 \text { Maringá a } \\
\text { Francisco Alves }\end{array}$} \\
\hline $\begin{array}{c}\text { Goetze } \\
\text { Engenharia Ltda. }\end{array}$ & $10 \%$ & & & & & \\
\hline $\begin{array}{c}\text { America } \\
\text { Empreendimentos }\end{array}$ & $10 \%$ & & & & & \\
\hline \multirow[t]{2}{*}{$\begin{array}{l}\text { Tucumann Eng. e } \\
\text { Empreendimentos }\end{array}$} & $10 \%$ & & & & & \\
\hline & & Total Km & & & 1.375 & \\
\hline $\begin{array}{c}\text { Grupos } \\
\text { controladores }\end{array}$ & Part. \% & Concessionárias & Prog. & UF & $\begin{array}{l}\text { Ext. } \\
\mathrm{Km} \text {. }\end{array}$ & Rodovias \\
\hline TRIUNFO & $100 \%$ & Concepa & Fed. & RS & 121 & $\begin{array}{c}\text { BR 290; RS; BR } \\
116 \mathrm{RS}\end{array}$ \\
\hline TRIUNFO & $100 \%$ & Econorte & PR & PR & 344 & $\begin{array}{c}\text { BR 369; } 153 ; \mathrm{PR} \\
323 ; 445 ; 090\end{array}$ \\
\hline TRIUNFO & $100 \%$ & Transbrasiliana & Fed. & SP & 322 & BR 153 SP \\
\hline TRIUNFO & $100 \%$ & Concebra & Fed. & DF/GO/MG & 1.176 & $\begin{array}{c}\text { BR 153/ BR 060/ } \\
\text { BR } 262 \text { DF;GO; } \\
\text { MG }\end{array}$ \\
\hline TRIUNFO & $62,50 \%$ & \multirow{4}{*}{ Concer } & \multirow{4}{*}{ Fed. } & \multirow{4}{*}{$\mathrm{RJ} / \mathrm{MG}$} & \multirow{4}{*}{180} & \multirow{4}{*}{ BR 040} \\
\hline Construcap & $18 \%$ & & & & & \\
\hline CM SAA & $10,5 \%$ & & & & & \\
\hline \multirow[t]{2}{*}{$\mathrm{CCl}$ Concessões } & $9 \%$ & & & & & \\
\hline & & Total km & & & 2.143 & \\
\hline $\begin{array}{l}\text { Odebrecht } \\
\text { Transport }\end{array}$ & $50 \%$ & \multirow[t]{2}{*}{ Rota do Atlântico } & \multirow[t]{2}{*}{ PE } & \multirow[t]{2}{*}{ PE } & \multirow[t]{2}{*}{44} & \multirow{2}{*}{$\begin{array}{l}\text { Complexo Viário } \\
\text { e Logístico de } \\
\text { Suape }\end{array}$} \\
\hline Invepar & $50 \%$ & & & & & \\
\hline $\begin{array}{l}\text { Odebrecht } \\
\text { Transport }\end{array}$ & $50 \%$ & \multirow[t]{2}{*}{ Bahia Norte } & \multirow[t]{2}{*}{ BA } & \multirow[t]{2}{*}{ BA } & \multirow[t]{2}{*}{121} & \multirow{2}{*}{$\begin{array}{c}\text { BR 093; 512; 521; } \\
\text { 524; 526; } 535\end{array}$} \\
\hline Invepar & $50 \%$ & & & & & \\
\hline CCR & $33,30 \%$ & \multirow{3}{*}{ Via Rio } & \multirow{3}{*}{ RJ } & \multirow{3}{*}{ RJ } & \multirow{3}{*}{13} & \\
\hline $\begin{array}{l}\text { Odebrecht } \\
\text { Transport }\end{array}$ & $33,40 \%$ & & & & & $\begin{array}{l}\text { via expressa da } \\
\text { Barra da Tijuca }\end{array}$ \\
\hline Invepar & $33,30 \%$ & & & & & \\
\hline Encalso & $60 \%$ & Renovias & $\mathrm{SP}$ & $\mathrm{SP}$ & 346 & SP 340; 342; 344; \\
\hline Renovias & $40 \%$ & nertuvias & $J$ & Jr & 340 & $350 ; 215$ \\
\hline & & Total km & & & 524 & \\
\hline
\end{tabular}

Fonte: $A B C R, 2015$. 
Tabela 2: Grupos controladores independentes de concessionárias de rodovias no Brasil - 2015.

\begin{tabular}{|c|c|c|c|c|c|c|}
\hline Independentes & $\begin{array}{l}\text { Part. } \\
\%\end{array}$ & Concessionárias & Prog. & UF & $\begin{array}{l}\text { Ext. } \\
\text { Km. }\end{array}$ & Rodovias \\
\hline BR Vias & $100 \%$ & Via Rondon & SP & SP & 413 & SP 300 \\
\hline $\begin{array}{l}\text { Cartelloni; America } \\
\text { Grin; Codinex }\end{array}$ & & $\begin{array}{l}\text { Caminhos do } \\
\text { Paraná }\end{array}$ & PR & PR & 406 & $\begin{array}{c}\text { BR 277; BR } \\
373 ; 476 ; \text { PR } \\
427 ; 438\end{array}$ \\
\hline $\begin{array}{c}\text { Colimex; Tervap; ES } \\
\text { 060; CC Vitória }\end{array}$ & & Rodosol & ES & ES & 68 & ES 060 \\
\hline ACIONA & $100 \%$ & Rodovia do Aço & Fed. & RJ & 200 & BR 393 RJ \\
\hline $\begin{array}{l}\text { Delta Construções } \\
\text { Oriente Construções }\end{array}$ & $\begin{array}{l}50 \% \\
50 \%\end{array}$ & Rota 116 & RJ & RJ & 140 & RJ 104; RJ 116 \\
\hline $\begin{array}{l}\text { Torc Terraplanagem } \\
\text { Emp. Constr. Brasil } \\
\end{array}$ & $\begin{array}{l}50 \% \\
50 \% \\
\end{array}$ & TEBE & SP & SP & 156 & $\begin{array}{l}\text { SP 323; SP } \\
326 ; \text { SP } 351\end{array}$ \\
\hline Isolux Corsan & $50 \%$ & \multirow[b]{2}{*}{ Via Bahia } & \multirow[b]{2}{*}{ BA } & \multirow[b]{2}{*}{ BA } & \multirow[b]{2}{*}{681} & BR 324; \\
\hline $\begin{array}{c}\text { Encalso } \\
\text { Infravix Partic. } \\
\end{array}$ & $\begin{array}{ll}23 \% \\
22 \% \\
\end{array}$ & & & & & $\begin{array}{c}\text { BR 116; } \\
\text { BA 526; } 528 \\
\end{array}$ \\
\hline $\begin{array}{c}\text { Carioca; Queiroz } \\
\text { Galvão; Strata; Cowan }\end{array}$ & & Viapar & PR & PR & 547 & $\begin{array}{l}\text { BR 369; 376; } \\
\text { PR 444; } 317\end{array}$ \\
\hline $\begin{array}{l}\text { Estrutural; Kamilos; } \\
\text { Ellenco; Greca }\end{array}$ & & MGO Rodovias & Fed. & MG/GO & 437 & $\begin{array}{l}\text { BR 050 } \\
\text { GO/MG } \\
\end{array}$ \\
\hline $\begin{array}{c}\text { Contern } \\
\text { Cibe }\end{array}$ & $\begin{array}{l}74 \% \\
26 \%\end{array}$ & SP Mar & SP & SP & 99 & $\begin{array}{l}\text { SP 021; SPA } \\
086 ; 021\end{array}$ \\
\hline & & Total km & & & 3.143 & \\
\hline
\end{tabular}

Fonte: $A B C R, 2015$.

A seguir analisaremos os sete maiores grupos e conglomerados e duas grandes empresas ${ }^{11}$ que atuam em concessões de rodovias no Brasil. A tabela 3 mostra o total de quilômetros de rodovias administrados por cada grupo ou conglomerados ou grande empresa.

Tabela 3: Grupos que atuam em concessões de rodovias no Brasil.

\begin{tabular}{l|l|l}
\multicolumn{1}{c|}{ Grupo } & \multicolumn{1}{c|}{$\begin{array}{c}\text { Quilometragem de rodovias } \\
\text { administradas }\end{array}$} & Ano de fundação \\
\hline AB Concessões S.A. & 1.500 & 2012 \\
\hline Arteris & 3.250 & 1997 \\
\hline CCR Concessões & 3.284 & 1998 \\
\hline Ecorodovias & 1.792 & 1997 \\
\hline Invepar & 821 & 2000 \\
\hline Odebrecht Transport & $1.405,50$ & 2010 \\
\hline Triunfo & $2.139,50$ & 1999 \\
\hline Total & 14.192 & \\
\hline
\end{tabular}

Fonte: AB Concessões, Arteris, CCR, EcoRodovias, Invepar, Odebrecht TransPort e Triunfo, 2015.

${ }_{11}$ A Odebrecht TransPort e a AB Concessões não são classificadas como grupos ou conglomerados, uma vez que com base em Santos (2013) não possuem uma diversificação dos setores em que atuam que justifique serem chamadas de grupos ou conglomerados. 


\section{ARTERIS}

Desde o ano de 2012 todas as concessionárias da OHL no Brasil passaram para o controle da Arteris que por sua vez possui capital aberto no Novo Mercado da Bovespa e suas ações são divididas em 51\% para a Abertis Infraestruturas S.A. e 49\% pela Brooksfield Motorways Holdings SRL. Atualmente a Abertis administra em torno de 3.200 quilômetros de rodovias no Brasil.

A Abertis possui sede na Espanha. Ao todo são doze as concessionárias do grupo Abertis na América Latina sendo nove concessionárias no Brasil e três no Chile. No mundo controlam em torno de 7.000 quilômetros de rodovias. Em 2014 a Abertis possuía negócios nos seguintes países: Argentina, Brasil, Canadá, Chile, Colômbia, Espanha, Estados Unidos, França, Irlanda, Itália, Porto Rico e Reino Unido. Ao total controla 28 concessionárias no mundo, no Brasil o nome fantasia do grupo é Arteris e controla as seguintes concessionárias: Autovias, Centrovias, Intervias, Vianorte, Fernão Dias, Fluminense, Litoral Sul, Planalto Sul e Régis Bittencourt.

A Abertis foi criada em 2003 como administradora de infraestruturas e entre 2008 e 2013 adquiriu 57,7\% da Hispasat o que levou a empresa a ser a primeira acionista de operadores de satélites da Espanha. No ano de 2012 adquiriu o consórcio Metropistas em Porto Rico que opera as rodovias PR-22 e PR-5. Em 2013 integraram à sua administração as rodovias operadas pela OHL no Brasil e no Chile (ABERTIS, 2014).

Em meados de 2015 possuía 344.444 ações ordinárias. O ativo total em junho de 2015 foi de $\mathrm{R} \$ 4.381,760$ e em 31 de dezembro de 2014 era de $\mathrm{R} \$ 3.987,530$; apresentou, portanto, um crescimento de 9,88\% em seis meses. O balanço financeiro da Arteris dos dois primeiros trimestres de 2015 foi de lucro líquido de $\mathrm{R} \$ 112,481$ milhões de reais, deste valor $\mathrm{R} \$ 58,183$ foi referente ao segundo trimestre. O acumulado do primeiro semestre de 2014 foi de $\mathrm{R} \$ 188,081$ milhões de reais. Uma diferença de $\mathrm{R} \$ 75,6$ milhões a menos ${ }^{12}$. No entanto, o resultado do segundo trimestre de 2015 referente a receita obtida com pedágio Earnings Before Interest, Taxes, Depreciation and Amortization (EBTIDA) ${ }^{13}$ foi de 319,159 milhões de reais, se comparada com o mesmo período de 2014 teve um aumento de 6,6\%. Já na demonstração das mudanças do patrimônio líquido (DMPL) o resultado em 30 de junho (referente ao período 1 de janeiro a 30 de junho de 2015) foi de R $\$ 1.316,365$ de reserva de lucro e de R $\$ 2.167,916$ de patrimônio líquido. Para o mesmo período de 2014 o resultado foi de $\mathrm{R} \$ 1.155,786$ e 1.928,203 respectivamente (1TR15 ARTERIS, $2015^{14}$ ).

\footnotetext{
${ }_{12}$ Esses valores se referem a demonstrações financeiras individuais.

13 O significado da sigla EBTIDA é lucros antes de juros, impostos, depreciação e amortização. Ou seja, mostra o quanto uma empresa gera de recursos por meio de suas atividades operacionais sem contar impostos e outros efeitos financeiros.

14 1TR15 é uma sigla referente ao primeiro relatório trimestral do ano de 2015 da Arteris.
} 
Conforme informações do 1TR15 e 2TR15 Arteris, referentes ao primeiro e ao segundo trimestre de 2015, em relação à Receita de Pedágio houve "crescimento de 1,1\% com um total de $\mathrm{R} \$ 588,1$ milhões. No acumulado do ano o aumento foi de 2,6\% com um montante de R\$1,2 bilhão. A melhora está relacionada aos reajustes de tarifas entre os períodos - em algumas concessões acima da inflação" (p. 20). Esse reajuste acima da inflação decorreu de reequilíbrio econômico-financeiros dos contratos, muitos deles para remunerar investimentos adicionais para a melhoria e readequação da infraestrutura das rodovias federais.

A receita bruta total da Arteris no primeiro semestre de 2015 foi de R $\$ 1,9$ bilhão de reais. Em relação ao endividamento a Arteris está realizando obras que totalizam no primeiro semestre de 2015 a inversão de $\mathrm{R} \$ 900,8$ milhões de reais nas concessões sob sua gestão. No entanto, desse total foram utilizados $\mathrm{R} \$ 85,4$ milhões tomados de empréstimo do BNDES, e ainda tem um saldo de R 449 milhões a ser utilizado em 2015. O total em inversões previstas pela Arteris em 2015 é de aproximadamente R 2 bilhões.

\section{CCR CONCESSÕES}

A CCR Concessões (Companhia de Concessões Rodoviárias) é um dos maiores grupos nacionais que atuam no segmento de concessões de rodovias. A CCR foi criada em 1998, ano em que foi iniciada a primeira etapa do programa de concessões do Estado de São Paulo. A estrutura acionária da CCR possui a composição mostrada no quadro 1. Este grupo econômico é formado por três outros grupos. Soares Penido que também tem participação no grupo Serveng (estes dois grupos tiveram a iniciativa de Pelerson Penido, falecido em 2012). Camargo Corrêa que se originou na cidade de Jaú, no interior do Estado de São Paulo por meio do encontro entre Sebastião Camargo e de Sylvio Brand Côrrea em 1939 ao fundarem a Camargo Côrrea \& Cia. Ltda. - Engenheiros e Construtores (SPOSITO e SANTOS, 2012). E o outro grupo é o Andrade Gutierrez que foi fundado em 1948 por meio da associação entre os irmãos Gabriel e Roberto Andrade e Flávio Gutierrez, todos engenheiros.

Quadro 1: Composição acionária da CCR - 2015.

\begin{tabular}{|c|c|}
\hline Acionistas & Participação em \% \\
\hline Grupo Soares Penido & 17,22 \\
\hline Grupo Camargo Correia & 17 \\
\hline Grupo Andrade Gutierrez & 17 \\
\hline Total negociado na BM\&FBovespa & 48,7 \\
\hline Total & 100,00 \\
\hline
\end{tabular}

Fonte: CCR, 2015. 
A CCR se autodenomina uma das maiores empresas de concessões do mundo, e isto é verdade devido a sua atuação internacional no setor, a empresa administra 3.284 quilômetros no Brasil nos estados de São Paulo, Paraná, Rio de Janeiro e mais recentemente no Mato Grosso do Sul, uma vez que venceu o leilão de concessão do trecho da BR 163 localizado no estado. A CCR também possui 34,25\% dos ativos da STP que opera os meios eletrônicos de pagamento do sistema Sem Parar e Via Fácil e 45\% do capital Social da Controlar, que é a empresa responsável pela inspeção veicular ambiental em toda a frota do município de São Paulo (CCR, 2013).

Além do segmento de concessões de rodovias, a CCR atua com os de mobilidade urbana e serviços, com valor de mercado superior a 20 bilhões. A CCR está presente também no setor de transporte de passageiros por meio das concessionárias ViaQuatro (Metrô de São Paulo, linha 4 Amarela), CCR Barcas (transporte aquaviário no Rio de Janeiro) e CCR Metrô Bahia (Metrô de Salvador e Lauro de Freitas) também tem participação no Veículo Leve sobre Trilhos (VLT) Carioca (GRUPO CCR, 2014).

Em 2012 o Grupo iniciou sua participação no sistema aeroportuário. Conforme informações do Grupo CCR “com a aquisição de participação acionária nas concessionárias dos aeroportos internacionais de Quito (Equador), San Jose (Costa Rica) e Curaçao. No Brasil, possui a concessionária $\mathrm{BH}$ Airport responsável pela administração do Aeroporto Internacional de Belo Horizonte, em Confins, Minas Gerais” (CCR, 2014).

Em relação às concessões de rodovias o Grupo CCR possui dez empresas concessionárias no Brasil a maioria no Estado de São Paulo, apenas a ViaLagos e a Ponte que ficam no Estado do Rio de Janeiro e a MSVia que é a nova empresa do Grupo. A MSVia iniciou suas operações em abril de 2014 ao ganhar a concessão da BR 163 que é localizada no Estado do Mato Grosso do Sul. Essa nova empresa terá que duplicar mais de 800 quilômetros de extensão da BR 163 em um prazo de cinco anos.

Em relação aos lucros da CCR pode-se dizer que é bastante considerável. No ano de 2014 a empresa totalizou um lucro líquido de R $\$ 1,348$ bilhão e no ano de 2013 o lucro foi de $\mathrm{R} \$ 1,351$ bilhão, ou seja, ficou praticamente estável (EXAME, 2015). Esses valores permitem afirmar que as concessões são negócios extremante lucrativos e com risco muito baixo, uma vez que contam com proteção estatal em casos de reduções de VDM abaixo do previsto nas projeções realizadas antes da assinatura do contrato. Esse fato mostra que os grandes grupos econômicos estão diversificando seus negócios partindo para setores como o de concessões de infraestruturas. Esse setor tem se revelado mais seguro do que o setor produtivo, não por acaso empresas como a Odebrecht tenha diversificado suas linhas de investimento e entrado nesse ramo de negócios. 
Conforme resultados do 1TR15 da CCR, o EBTIDA ajustado apresentou crescimento de 2,8\% e o lucro líquido na mesma base de R $\$ 312,6$ milhões de reais. Nestes cálculos "ajustados na mesma base" não incluem os resultados do Aeroporto de Confins, novos negócios que ainda não estão operacionalizados: Metrô Bahia e a MSVia, não recorrente da provisão tributária da Ponte (Rio-Niterói); e adicionalmente no lucro e nas comparações pró-forma, exclui Controlar, ViaRio e VLT. A análise do 1TR15 traz comparações com os relatórios 1TR12, 1TR13 e 1TR14 em relação à origem das receitas da CCR o que mostra que tem diminuído a porcentagem oriunda dos pedágios, uma das razões é a diversificação dos negócios do grupo. Para exemplificar, no 1TR12, 91\% do breakdown da receita bruta provinha de pedágios e no 1TR15 esse valor caiu para 79\%, já no breakdown do 2 TR15 esse valor caiu para $78 \%$.

A análise dos resultados apresentados no 2TR15 mostrou que o EBTIDA ajustado na mesma base no período foi de crescimento de 4,9\% e o lucro líquido ajustado na mesma base foi de 284,6 milhões. A CCR também tem ampliado seus clientes do sistema STP ${ }^{15}$ conforme resultados do 1 TR15 e 2TR15, com crescimento de 11,3\% e 10,6\% respectivamente, comparados ao mesmo período de 2014.

\title{
INVEPAR
}

A Invepar é um grupo brasileiro que atua no segmento de concessões no Brasil e no Peru e ao todo administra 1.963 quilômetros de rodovias e vias urbanas nesses dois países. De acordo com informações da própria empresa,

\begin{abstract}
Atualmente o grupo Invepar é composto por 14 empresas: doze concessionárias de serviços públicos nas áreas de Rodovias, Aeroportos e Mobilidade Urbana e duas controladas 100\% pela Invepar - a PEX S/A, que administra o serviço de pagamento eletrônico de pedágio através do Passe expresso, e a Metrobarra S.A., que vai prover material rodante e sistemas para a operação da Linha 4 do Metrô do Estado do Rio de Janeiro, além de deter o direito de aquisição das ações da Concessionária Rio Barra S.A., atual concessionária da Linha 4 (INVEPAR, 2014).
\end{abstract}

A Invepar iniciou suas atividades no ano 2000 quando foi constituída para administrar duas concessões a LAMSA (Linha Amarela S.A) no Rio de Janeiro e a CLN (Concessionária Litoral Norte) na Bahia. No ano de 2009 a empresa incorporou a CART (que administra um trecho de 444 quilômetros da Rodovia Raposo Tavares SP 270, no Estado de São Paulo), nesse mesmo ano adquiriu o controle do MetrôRio e teve sua capacidade de investimento

15 Serviços e Tecnologia em Pagamento S.A. é uma empresa criada no ano 2000. 
potencializada em razão da Petros ${ }^{16}$ e da Funcef ${ }^{17}$ terem se tornado acionistas. A foto 9 mostra uma praça de pedágio da Cart na rodovia Raposo Tavares SP-270, que pertence à Invepar.

Em 2010 a Invepar incorpora mais duas concessões: a CBN (Concessionária Bahia Norte) e a CRT (Concessionária Rio Teresópolis) e em 2011 o consórcio Invepar-Odebrecth por meio da CRA (Concessionária Rota do Atlântico) ganha a licitação para administrar o complexo viário de acesso ao porto de Suape - Complexo Viário e Logístico Suape/Express Way, em Pernambuco. No ano de 2012 a Invepar inicia sua atuação no exterior ao incorporar a VPR Brasil Participações e assume a Lamsac (Línea Amarilla S.A.C) assinando um contrato no modelo BOT para a Vía Parque Rímac na região Metropolitana de Lima no Peru.

No ano de 2013 a Invepar vence a licitação para operar o VLT carioca que ligará a zona portuária ao centro financeiro da cidade do Rio de Janeiro. Nesse mesmo ano ganha o leilão da BR-040 que liga o Distrito Federal a Juiz de Fora em Minas Gerais. E em 2014 inicia a operação do Terminal 3 do Aeroporto Internacional de Guarulhos.

A Invepar é uma empresa que teve um crescimento significativo em pouco tempo. Por trás da empresa há investidores de grande porte, como é o caso da construtora OAS.

A tabela 4 apresenta a composição acionária da Invepar. A estrutura societária da Invepar possui quatro grandes sócios, os quais são: OAS (24,44\%), PREVI (25,56\%), FUNCEF (25\%) e PETROS (25\%). A PREVI também tem ações na Embraer e na Vale (LAZZARINI, 2011).

O capital social da Invepar é representado por 429,2 milhões de ações sendo 143,1 milhões ordinárias e 286,1 preferenciais (INVEPAR, 2015).

\footnotetext{
${ }_{16}$ A Petros “[...] foi fundada pela Petrobras em julho de 1970. É o segundo maior fundo de pensão do Brasil e pioneira no mercado de previdência complementar do país. Seu principal compromisso é assegurar uma renda de aposentadoria capaz de manter o padrão de vida de seus participantes no futuro com tranquilidade e segurança" (PETROS, 2014).

${ }_{17}$ A Fundação dos Economiários Federais (FUNCEF) é o terceiro maior fundo de pensão do Brasil. É uma "entidade fechada de previdência privada, sem fins lucrativos e com autonomia administrativa e financeira, foi criada com base na Lei $\mathrm{n}^{\circ} 6.435$, de 15 de julho de 1977, com o objetivo de administrar o plano de previdência complementar dos empregados da Caixa Econômica Federal" (FUNCEF, 2014).
} 
Tabela 4: Composição acionária da Invepar - 2015.

\begin{tabular}{c|c|c|c|c|c|c} 
Acionistas & ON* & $\%$ & PN & $\%$ & Total & $\%$ \\
$\begin{array}{c}\text { BB Fundo de } \\
\text { Investimento em Ações }\end{array}$ & 35.764 .281 & $25,00 \%$ & 73.939 .746 & $25,80 \%$ & 109.704 .027 & $25,60 \%$ \\
\hline OAS Infraestrutura S.A. & 35.764 .280 & $25,00 \%$ & 69.117 .380 & $24,20 \%$ & 104.881 .660 & $24,40 \%$ \\
\hline Construtora OAS S.A. & 1 & $0,00 \%$ & 1 & $0,00 \%$ & 1 & $0,00 \%$ \\
\hline PETROS & 35.764 .281 & $25,00 \%$ & 71.528 .561 & $25,00 \%$ & 107.292 .842 & $25,00 \%$ \\
\hline FUNCEF & 35.764 .281 & $25,00 \%$ & 71.528 .561 & $25,00 \%$ & 107.292 .842 & $25,00 \%$ \\
\hline Total & 143.057 .124 & $100 \%$ & 286.114 .248 & $100 \%$ & 429.171 .372 & $100 \%$ \\
\hline
\end{tabular}

*Ordinárias.

**Preferenciais.

Fonte: INVEPAR, 2015.

A Invepar registrou no primeiro trimestre de 2015 (período compreendido entre os dias primeiro de janeiro e o dia 30 de março) um total de 59,3 milhões de veículos pagantes de pedágio nas rodovias que administra. Mesmo que esse total tenha sido 0,2,\% inferior ao mesmo período do ano anterior é um número muito elevado de veículos pagantes. De acordo com o 1TR15 (primeiro relatório trimestral de 2015) da Invepar as causas desse decréscimo se devem aos seguintes fatores:

(i) queda da atividade econômica do país; (ii) greve dos caminhoneiros, ocorrida na $2^{\text {a }}$ quinzena de fevereiro, que refletiu negativamente no tráfego de veículos pesados entre os trimestres, impactando o resultado operacional do segmento. A CART apresentou uma queda de $5,4 \%$ no $\mathrm{VEP}^{18}$ total do trimestre, sendo compensada principalmente pela CRA ${ }^{19}$, com um aumento de $4,9 \%$, pela CLN, com variação positiva de $4,7 \%$ e pela CBN, com $+1,0 \%$.

Em relação ao número de passageiros transportados nas empresas de transporte urbano administradas pela Invepar foi registrado um total de 52,3 milhões. Um aumento de 2,3 milhões $(7,4 \%)$ em relação ao mesmo período do ano anterior. Nos aeroportos administrados pela Invepar foi registrado aumento de 0,2 milhão $(1,9 \%)$ de passageiros a mais que no ano anterior.

A receita líquida da Invepar no 1TR15 foi de 794,3 milhões de reais. Na comparação com o mesmo período do ano anterior houve um aumento de $16,4 \%$. No 2TR15 teve aumento em relação ao mesmo período de 2014 (aumento de 8,9\%) e em relação ao 1TR15, a receita líquida para esse período foi de $\mathrm{R} \$ 804,7$ milhões. Os aumentos foram registrados em todos os segmentos de atuação da Invepar, os quais são: rodovias (16,6\%), mobilidade

18 Veículos Equivalentes Pagantes (VEP).

19 Concessionária Rota do Atlântico. 
urbana (13,6\%) e aeroportos (3,5\%). A receita líquida da Invepar em 2014 foi de R\$3,0 bilhões, e obteve um crescimento de 23,5\% em relação ao ano de 2013 (INVEPAR, 2015). A Invepar atua nos seguintes estados brasileiros: Minas Gerais, São Paulo, Paraná, Rio de Janeiro, Goiás, Bahia, Pernambuco e no Distrito Federal.

\section{ODEBRECHT TRANSPORT}

A Odebrecht é outro grande grupo que tem aumentado sua participação no setor de administração de infraestruturas de transportes e por meio da Odebrecht Infraestrutura - Brasil atua no setor de infraestrutura de transportes. Devido ao grande porte a empresa atua em todos os segmentos e fases das infraestruturas desde a elaboração do projeto até a construção e a operação. A empresa opera nos segmentos de transporte, energia, logística, saneamento, desenvolvimento urbano e edificações de uso público e corporativo.

A Odebrecht TransPort também está no setor da mobilidade urbana, portos, rodovias, sistemas integrados de logística e aeroportos. A empresa possui 5.100 integrantes e 20 ativos em vários estados do Brasil. A Odebrecht TransPort foi criada em 2010 e conta com quatro ativos, sendo um dos principais o Fundo de Investimento do Fundo de Garantia Por Tempo de Serviço (FI-FGTS) com 30\% de participação no capital (ODEBRECHT TRANSPORT, 2015).

A Odebrecht TransPort é uma empresa de capital fechado e sua estrutura societária é mostrada no quadro 2. Dos sete grandes grupos a Odebrecht Transport e a AB Concessões S.A. são as únicas que não possuem capital aberto na $\mathrm{BMF} \&$ Bovespa, caso a $\mathrm{AB}$ Concessões abra seu capital em 2016 a Odebrecht será o único grande grupo com capital fechado.

No setor de administração rodoviária a Odebrecht TransPort controla sete concessionárias: Rota do Oeste, Rota das Bandeiras, Rota dos Coqueiros, Rota do Atlântico, Rota das Fronteiras, Bahia Norte, Litoral Norte e ViaRio e tem participação na ConectCar ${ }^{20}$. Outro ramo de atuação da Odebrecht TransPort é por meio da empresa Otima que é responsável pela instalação e manutenção de abrigos para passageiros de ônibus na cidade de São Paulo. Por meio de participação da Logum a Odebrecht TransPort detém 20\% das ações. A Logum é responsável pela construção e operação do sistema logístico multimodal de Etanol que prevê a construção de corredores de transporte dutoviário entre a região Centro Oeste e as regiões de grande consumo e a costa brasileira (ODEBRECHT TRANSPORT, 2015). A Odebrecht TransPort opera nos seguintes estados brasileiros: São Paulo, Rio de Janeiro, Espírito Santo, Minas Gerais, Paraná, Goiás, Pernambuco, Bahia e Mato Grosso.

20 O Conect Car é uma tecnologia de identificação automática de veículos (IAV) que permite que o automóvel seja reconhecido nos pedágios e estacionamentos conveniados. 
Quadro 2: Composição acionária da Odebrecht TransPort - 2015.

\begin{tabular}{l|c}
\multicolumn{1}{c|}{ Acionistas } & Participação em \% \\
\hline Odebrecht S.A & 59,39 \\
\hline FI-FGTS & 30,00 \\
\hline BNDESPAR & 10,61 \\
\hline
\end{tabular}

Fonte: Odebrecht TransPort, 2015.

A Odebrecht está presente no setor de concessões de rodovias e há mais de 30 anos nos setores de energia, saneamento e nos últimos anos no de rodovias. Após seis anos sem participar de concessões de rodovias, com a venda de sua parte na CCR em 2003, voltou ao segmento em 2009 ao vencer o leilão do Corredor Dom Pedro I localizado no interior do Estado de São Paulo.

Conforme já destacado suas operações nesse setor iniciaram no ano 2000. Em 2010 é criada a Odebrecht TransPort, neste mesmo ano a Odebrecht inicia participação na concessionária Bahia Norte que foi vencedora do leilão do Sistema BA-093, que interligam diversos municípios da Região Metropolitana de Salvador: Mata de São João, Pojuca, Dias D'Avila, Camaçari, Simões Filho, Lauro de Freitas, Candeias e Salvador (BAHIA NORTE, 2014). A Odebrecht TransPort tem aumentado sua participação no setor de administração de infraestruturas. Nesse sentido, vale lembrar que ainda haverá concessões de rodovias, portos e aeroportos, de acordo com os objetivos do Governo Federal anunciados em meados de 2015. Estes grandes grupos certamente participarão desses futuros leilões.

A Odebrecht viu no setor de infraestruturas uma importante via de negócios, conforme afirmação de Marcelo Odebrecht no relatório anual da holding,

Por meio de Parceria Público-Privadas e de concessões aprofundamos de modo contundente a diversificação de nossos negócios, hoje, operamos transportes urbanos, rodovias, portos, aeroportos, sistemas de água e saneamento básico, sistemas de irrigação, distribuição de energia elétrica e arenas multiuso, entre outros serviços (2014, p. 22).

A Odebrecht TransPort já possui 20 empresas em seu portfólio. Embora, representava 1,9\% da receita bruta da Odebrecht que foi de R \$ 96,930 bilhões de reais em 2013. Em razão de ser uma empresa de capital fechado a Odebrecht TransPort não disponibiliza relatórios trimestrais e anuais sobre o detalhamento de seus negócios, endividamentos, lucros etc. 


\title{
ECORODOVIAS
}

A EcoRodovias também é um grupo de grande porte que integra o rol das maiores empresas do setor de infraestruturas de transportes no Brasil. A EcoRodovias é uma empresa que se autodenomina como uma companhia de infraestrutura logística integrada e opera ativos de logística intermodal, concessões rodoviárias e serviços correlatos. A EcoRodovias foi criada em 1997 pela Primav construções e Comércio Ldta., do Grupo CR Almeida, sendo que esta última já atuava no mercado de construção pesada. A partir de 1998 passou a contar com a parceria de uma empresa Europeia, a Impregilo International N.V., do Grupo Impregilo S.p.A que é a maior construtora de capital aberto da Itália.

A EcoRodovias tem foco nas rodovias que são corredores de exportação e em importantes eixos turísticos, conforme declaração da própria empresa.

\begin{abstract}
Desde 1997, quando passou a operar no setor de concessão de rodovias, a empresa buscou administrar corredores de importação e exportação e importantes eixos turísticos. A primeira experiência da empresa, já com foco nessa estratégia, se deu ainda em 1997, quando o grupo passou a controlar a Ecovia Caminho do Mar, concessionária que administra 176 quilômetros de rodovias entre a capital paranaense e o Porto de Paranaguá. Em 1998, a EcoRodovias conquistou mais duas concessões: a Ecovias dos Imigrantes, que opera a principal ligação da região metropolitana de São Paulo com o Porto de Santos, o Polo Petroquímico de Cubatão e as praias da Baixada Santista; e a Ecosul, concessionária que administra o Polo Rodoviário de Pelotas, no Rio Grande do Sul, acesso ao Porto de Rio Grande e ao litoral gaúcho (ECORODOVIAS, 2015).
\end{abstract}

Em 2003 a EcoRodovias abre seus capitais na BM\&F/Bovespa. Em 2006 inicia suas atividades no setor logístico com a criação do Ecopátio Cubatão e em 2007 com a construção do Ecopátio Imigrantes. Em 2010, por meio da Elog, adquire parte da operação do grupo Colúmbia. Em 2012 a EcoRodovias adquire o terminal portuário do antigo complexo Tecondi que na época era o terceiro maior terminal de contêineres do porto de Santos. Atualmente o nome do complexo é Ecoporto Santos (ECORODOVIAS, 2015).

O grupo EcoRodovias possui seis concessionárias de rodovias no Brasil: Eco 101, Ecovia, Ecovias, Ecosul, Ecopistas, Ecocataratas, 14 unidades de logística que são controladas pela Elog localizadas nas regiões Sul e Sudeste e a Ecoporto (terminal de contêineres). O grupo EcoRodovias tem ainda participação na STP - Sem Parar/Via Fácil e tem como principal acionista a Primav Construções e Comércio S.A. (do Grupo Almeida).

O grupo atua nos seguintes estados brasileiros: São Paulo, Rio de Janeiro, Espírito Santo, Paraná e Rio Grande do Sul. A EcoRodovias controla as infraestruturas mais cruciais para as operações logísticas no Brasil como, por exemplo, o rodoanel em São Paulo, tem parte do controle do porto de Santos por meio da Ecoporto, controlam também o sistema rodoviário 
Anhanguera-Imigrantes e o corredor Ayrton Senna/Carvalho Pinto (rodovia SP 070) que liga a região metropolitana de São Paulo ao Vale do Paraíba e ao litoral norte do estado.

\section{TRIUNFO}

Outro grande grupo do setor de administração de infraestruturas é a Triunfo, que tem crescido nos últimos anos. A concessão mais extensa do Brasil teve como vencedora do leilão a Triunfo trata-se do lote que inclui trechos das rodovias BR-060, BR-262, BR153 com trechos localizados no Distrito Federal e nos Estados de Goiás e Minas Gerais. A parte da BR 153, que é localizada no Estado de São Paulo, foi administrada entre 2008 e 2014 pela concessionária Transbrasiliana que era da SPVias, porém a Triunfo adquiriu essa concessão em 2014 e então passou a administrar a BR 153 no trecho entre Anápolis e a divisa entre os Estados de São Paulo e Paraná (entre Anápolis - GO e Brasília - DF a ligação é pela BR 060).

A Triunfo Participações e Investimentos tem atuação em segmentos semelhantes aos de outros grupos como a Invepar e a Odebrecht TransPort e, também, possui capital aberto na Bolsa de Valores. A Triunfo Participações e Investimentos foi constituída em 1999 e incorporou as concessionárias Concepa, Concer e Econorte que pertenciam a construtora Triunfo. Em 2001 adquiriu 16,67\% da Portonave S.A. em 2002 entra no ramo de energia ao constituir a Rio Verde Energia e no mesmo ano obtém o registro de companhia aberta na Comissão de Valores Mobiliários (CVM).

Em 2005 a Triunfo Participações e Investimentos adquire participação adicional na Econorte, passando de 25\% para 50\%. Em 2007 aumenta sua participação na Portonave passando para 50\%. Ainda em 2007 a Rio Verde vende a totalidade da energia da Usina Hidrelétrica (UHE) Salto, pelo período de 16 anos para a Votener, empresa do Grupo Votorantim (TRIUNFO, 2015). Também no ano de 2007 ano realiza sua oferta pública inicial no segmento do Novo Mercado da BM\&FBovespa e passa a deter 100\% da Econorte.

Em 2008 a Triunfo Participações e Investimentos adquire 30\% das ações da Concepa e passa a ter a totalidade das ações. Em 2009 há nova expansão dos negócios ao adquirir a embarcação Norsul Atlântico e inicia operações no segmento da cabotagem por meio da Maestra Navegação e Logística. Em 2010 a empresa passa a ter o direito de explorar a Usina Hidrelétrica Garibaldi, em Santa Catarina e constitui a Rio Canoas Energia S.A. em 2011 juntamente com a Vetorial Participações e a América Latina Logística (ALL) cria a Vetria Mineração (TRIUNFO, 2015). 
Em 2012 a Triunfo Participações e Investimentos entra no ramo de aeroportos ${ }^{21}$ ao vencer o leilão para expansão, manutenção e operação do Aeroporto Internacional de Viracopos (em parceria com a UTC Participações S.A. e a Egis Airport Operation) e também expande os negócios no ramo de portos ao adquirir o direito de exploração de superfície sobre a área em que está situado o terminal da Portonaus.

Em 2013 ocorre a entrada do BNDESPAR no capital social da Triunfo com 14,8\% de participação, por meio de aumento de capital no valor de 330 milhões. Nesse mesmo ano vence o leilão para administrar as rodovias BR 153, BR 060 e BR 262 localizadas no Distrito Federal e nos Estados de Minas Gerais e Goiás. Em 2014 realiza parceria com Furnas para administrar a Usina Hidrelétrica de Três Irmãos (localizada no município de Pereira Barreto - SP) (TRIUNFO, 2015).

A estrutura societária da Triunfo Participações e Investimentos é organizada conforme mostra o quadro 3:

Quadro 3: Composição acionária da Triunfo Participações e Investimentos - 2015.

\begin{tabular}{l|c}
\multicolumn{1}{c|}{ Acionistas } & Participação em \% \\
\hline Triunfo Holding de Participações S.A. & 55,50 \\
\hline Controladores e administradores & 2,60 \\
\hline BNDESPAR & 14,80 \\
\hline Novo Mercado BM\&FBovespa & 27,10 \\
\hline
\end{tabular}

Fonte: Triunfo, 2015.

A Triunfo administra atualmente 2.139,5 quilômetros de rodovias no Brasil. Estão sob seu controle cinco concessionárias de rodovias. O quadro 4 mostra essas concessionárias.

Quadro 4: Empresas ligadas à administração rodoviária controladas pela Triunfo Participações e Investimentos - 2015.

\begin{tabular}{|c|c|c|}
\hline \begin{tabular}{l}
0 \\
\hdashline \\
0
\end{tabular} & Empresas & Localização (unidade da federação) e extensão em km \\
\hline อั ภ่ & Concer & Rio de Janeiro e Minas Gerais, 180 km \\
\hline$\sum \underset{1}{1}$ & Triunfo Concepa & Rio Grande do Sul, 121 km \\
\hline & Triunfo Concebra & Distrito Federal, Goiás e Minas Gerais, 1.176,5 km \\
\hline & Triunfo Econorte & Paraná, 341 km \\
\hline & Triunfo Transbrasiliana & São Paulo, 321 km \\
\hline
\end{tabular}

Fonte: Triunfo, 2015.

${ }_{21}$ A Triunfo Participações e Investimentos possui 23\% de participação na gestão do Aeroporto Internacional de Viracopos, localizado no município de Campinas, por meio da concessionária Aeroportos Brasil Viracopos. 
O faturamento em pedágio foi de 170,6 milhões de reais no segundo trimestre de 2015 (abril a junho). Conforme informações da Triunfo no,

\begin{abstract}
Segmento de Rodovias: mesmo com a queda de 5,4\% no tráfego consolidado do trimestre, a receita de arrecadação de pedágio atingiu $\mathrm{R} \$ 170,6$ milhões $(+22,6 \%)$ no mesmo período. Considerando a receita de arrecadação pró-forma, incluindo o resultado da Triunfo Transbrasiliana no $2 \mathrm{~T} 14$, esse crescimento atingiu $+4,8 \%$ (R $\$ 162,8$ milhões no $2 \mathrm{~T} 14$ ). No dia 27 de junho, a Companhia deu início a cobrança de pedágio com 70 dias de antecedência nas 11 praças da Triunfo Concebra. Vale ressaltar que a queda do tráfego do período foi impactada pela Lei dos Caminhoneiros, que será compensado no desempenho financeiro das rodovias através de reajustes tarifários (TRIUNFO, 2015).
\end{abstract}

A Triunfo concentra mais da metade de suas ações no setor de concessões de rodovias. No segundo semestre de 2015 esse setor representava $61 \%$ das atividades, além de rodovias $17 \%$ referente à energia, $14 \%$ referente a portos e $8 \%$ referente a aeroportos.

A presença da Triunfo Participações no território brasileiro ocorre nos Estados de São Paulo, Minas Gerais, Rio de Janeiro, Goiás, Rio Grande do Sul, Paraná e no Distrito Federal.

\title{
AB CONCESSÕESS.A
}

Para finalizar resta analisar a $\mathrm{AB}$ Concessões S.A que é uma empresa que administra aproximadamente 1.500 quilômetros de rodovias no Brasil. Essa empresa é uma joint venture $^{22}$ formada pela Atlantia (empresa de origem italiana) e a Bertin. A Bertin surgiu na cidade de Lins, no interior do Estado de São Paulo, com a atividade de frigorífico e expandiu seus negócios para os setores de infraestrutura e energia, porém em 2009 venderam seus frigoríficos para a JBS. As concessionárias de rodovias pertencentes à AB Concessões S.A. são as seguintes: Triângulo do Sol (100\%), Rodovia das Colinas (100\%) e Rodovias do Tietê (50\%), no Estado de São Paulo e a Nascente das Gerais no Estado de Minas Gerais. Na AB Concessões S.A cada sócio tem uma participação de 50\%.

A Atlantia é a empresa que controla as rodovias que eram administradas pela Società Autoestradade Concessioni e Construzioni Autoestrade Sp.A. que fora criada em 1950 pelo governo da Itália. Em 1999 essa empresa estatal foi privatizada, sendo incorporada pela Autoestrada per Italia S.p.A. Em 2007 a Autoestrada S.p.A se torna a Atlantia S.p.A. Ao total são 4.100 quilômetros de rodovias administradas pela Atlantia na Itália, Chile, Brasil, Índia e Polônia. A Atlantia possui suas ações negociadas na bolsa de Milão.

\footnotetext{
22 "Joint venture é Expressão em inglês que significa "união de risco" e designa o processo mediante o qual pessoas, ou, o que é mais frequente, empresas se associam para o desenvolvimento e execução de um projeto específico no âmbito econômico e/ ou financeiro. Uma joint venture pode ocorrer entre empresas privadas, entre empresas públicas e privadas, e entre empresas públicas e privadas nacionais e estrangeiras. Durante a vigência da joint-venture, cada empresa participante é responsável pela totalidade do projeto. No caso brasileiro, esta modalidade foi estimulada especialmente durante os anos 70, envolvendo empresas privadas nacionais, empresas estatais e empresas estrangeiras" (SANDRONI, 1999, p. 315).
} 
Devido à ruína financeira da Bertin nos últimos seis anos a tendência para o futuro da $\mathrm{AB}$ Concessões S.A. é incerta. Entretanto, atualmente figura como um grande grupo atuante no setor de concessões de rodovias no Brasil. A participação da Bertin na AB Concessões S.A. e sua empresa do ramo de laticínios, a Vigor (processadora de lácteos), são os dois segmentos que tem apresentado melhores resultados nos últimos anos (EXAME, 2013). O PIL lançado em meados de 2015 pelo governo federal prevê investimento privado de até 213 bilhões de reais em projetos de rodovias, ferrovias, portos e aeroportos. Assim, há uma oportunidade para estes sete grupos analisados ampliarem ainda mais suas atuações nestes segmentos.

Os resultados financeiros de 2014 mostram que a AB Concessões S.A. obteve lucro líquido de $\mathrm{R} \$ 174,574$ milhões de reais. O total do ativo do grupo em 31 de dezembro de 2014 foi de $\mathrm{R} \$ 4.208,935$.

\section{CONSIDERAÇÕES FINAIS}

Esta análise da trajetória de cinco grandes grupos econômicos ou conglomerados e duas empresas que estão atuando no Brasil na área de administração de infraestruturas: Arteris, CCR, Invepar, Odebrecht TransPort (empresa), EcoRodovias, Triunfo Participações e Investimentos e $\mathrm{AB}$ Concessões S.A. (empresa), mostra que há tendência de oligopolização no setor de concessões de rodovias no Brasil. As últimas concessões realizadas no Brasil ficaram em sua maioria sob administração destes cinco conglomerados e duas empresas. Outro grande conglomerado que sinaliza interesse em investir em concessões de infraestruturas é o Galvão ${ }^{23}$, conforme afirmamos, em 2014 venceram o primeiro leilão de rodovias referente à BR 153 em trecho de 624 quilômetros localizado nos Estados de Goiás e do Tocantins.

A gestão de infraestruturas tem sido um segmento de negócios muito atrativo ao grande capital. Os contratos elaborados no Brasil são bastante seguros em razão da proteção jurídica que oferece às empresas concessionárias, principalmente no que se refere às possíveis reduções de VDM nas rodovias em concessão. Conforme mostrado por Derani (2005) no Brasil a lei de privatizações e concessões não prevê limite para a participação estrangeira.

${ }_{23}$ “É a mais nova frente de atuação do Grupo Galvão, concebida como um eixo adjacente à prestação de serviços desempenhada pelas nossas demais empresas. Pela capacidade de geração contínua de caixa, resultante da execução de contratos de longo prazo, o setor dará contribuição importante à estabilidade financeira do Grupo. Temos como foco prioritário a participação em concessões de ferrovias, rodovias, portos e aeroportos, setores que, nos últimos anos, têm apresentado oportunidades crescentes para a atuação da iniciativa privada. Nossa primeira conquista nessa área se deu em 2014, com a vitória no leilão de trecho de 624,8 quilômetros da Rodovia BR-153 entre Anápolis (GO) e Aliança do Tocantins (TO). O contrato, que prevê a recuperação e a duplicação da estrada e sua operação por 30 anos, é o maior empreendimento de longo prazo do Grupo nos dias atuais" (GRUPO GALVÃO, 2016 - grifo nosso). 
Embora a participação estrangeira no setor não seja tão expressiva, há um grande grupo que é a Arteris que atua no Brasil, a Atlantia S.p.A por meio da joint venture com a Bertin e a Impregilo S.A. por meio de sua participação na EcoRodovias. Vale mencionar que grupos brasileiros do setor estão se internacionalizando como é o caso da Invepar e da Odebrecht TransPort.

Uma observação vale ser feita quando se analisa as concessões como um negócio. $\mathrm{Na}$ verdade, não é um bom negócio apenas para as empresas privadas, mas, de certa forma, também para o Estado. A partir da década de 1970 a situação financeira dos países emergentes (chamados de subdesenvolvidos na época) se agravou com a crise do petróleo, do fordismo, do welfare state e de seus desdobramentos como a elevação dos juros da dívida externa desses países pelos Estados Unidos. Esses países emergentes foram pressionados a tomar atitudes frente à crise financeira e no Brasil também política com a transição de ditadura militar para a democracia. Uma das saídas foi a desestatização que foi agravada na década de 1990.

Assim, as concessões também foram e são adotadas a partir dos anos 2000 mais que a privatização. Para o Estado foi um negócio vantajoso, pois devido ao fato de as concessionárias serem empresas privadas devem pagar impostos e isso significa uma forma de parte do dinheiro dos usuários das rodovias concedidas ir para os cofres públicos. Somado a isso, há também os contratos que normatizam as chamadas concessões onerosas que transfere dinheiro das concessões diretamente ao Estado por meio do ônus pago pela concessionária, como são todos os contratos de concessões de rodovias firmados pelos Estados de São Paulo e do Rio de Janeiro.

Ao total são 8,65\% da tarifa de pedágio em impostos e tributos. Ou seja, as concessões funcionam como uma via de mão dupla beneficiando a iniciativa privada e o próprio Estado. Além destes 8,65\% de impostos, há mais aproximadamente 20\% de TIR (lucro) para as concessionárias (essa análise dos tributos pagos se refere às concessões do Estado de São Paulo). Somado a isto há também os custos para se cobrar o pedágio, que inclui a construção da praça, o pagamento aos funcionários e os gastos com energia elétrica e água. Assim, conclui-se que esta modalidade de gestão de infraestruturas não é viável, uma vez que o custo de arrecadação mais o lucro é muito elevado, restando uma pequena parcela para investimento em melhorias das infraestruturas.

Os contratos de concessão do Governo Federal nas gestões dos presidentes Lula (20022010) e de Dilma Rousseff (2011-2016) optaram pela concessão sem ônus, isso tornou as tarifas de pedágio mais baixas para os usuários. Também houve aumento das exigências 
em relação aos contratos feitos na gestão de Fernando Henrique Cardoso (1995-2001), uma vez que exige a duplicação de rodovias até o quinto ano do contrato, como são os casos das rodovias BR-163, BR 040 e BR 101. Porém, no pacote de concessões anunciado em 2015 o governo optou pelas concessões onerosas, caso mantenha a intenção, voltará ao modelo utilizado pela gestão FHC, apenas com a vantagem de TIR menor, em torno de $9 \%$ ao invés de $20 \%{ }^{24}$.

O Estado também se beneficia via BNDES e fundos de pensão. Alguns fundos de pensão de empresas estatais como a Petros, Previ e o Funcef investem em concessionárias de rodovias e até induzem fusões dessas empresas. Como vimos a Petros e a Funcef são acionistas da Invepar. Nesse jogo de interesses o próprio Estado tem interesse que as concessionárias obtenham lucros elevados.

\section{AGRADECIMENTOS}

Pesquisa financiada com auxílio da Fundação de Amparo à Pesquisa do Estado de São Paulo (FAPESP)

\section{REFERÊNCIAS}

1. AB CONCESSÕES S.A. Apresenta informações sobre o grupo AB Concessões S.A. Online, 2015. Disponível em: <http://www.abconcessoes.com.br/abconcessoes/web/default_pti. asp? idioma $=0 \&$ conta $=45>$. Acesso em: 21 out. 2015.

2. ABERTIS. Apresenta informações sobre a Abertis. Online: 2104. Disponível em: <http://www. abertis.com/que-es-abertis/var/lang/es/idm/8>. Acesso em: 21 mai. 2014.

3. ARTERIS. Apresenta informações sobre a Arteris. Online: 2104. Disponível em: <http://www. arteris.com.br/>. Acesso em: 21 mai. 2014.

4. ARTERIS. Informações trimestrais. 2015. Online, 2015. Disponível em: <http://ri.arteris.com. br/ptb/5197/49501.pdf>. Acesso em: 19 out. 2015.

5. BEHRING, Elaine Rossetti. Brasil em contra-reforma: desestruturação do Estado e perda de direitos. São Paulo: Cortez, 2008.

6. BENKO, Georges. Economia, espaço e globalização na aurora do século XXI. São Paulo: Hucitec, 1996.

7. CCR CONCESSÕES. Apresenta informações sobre o grupo CCR Concessões. Online, 2015. Disponível em: <http://www.grupoccr.com.br/>. Acesso em: 21 out. 2015.

24 O governo de Michel Temer anunciou no mês de setembro de 2016 um novo projeto de concessões denominado "Crescer" que pretende conceder aeroportos, portos, ferrovias e rodovias, áreas de exploração de petróleo e distribuidoras de energia (RIZÉRIO, 2016). 
8. CNT. Confederação Nacional do Transporte. Pesquisa CNT de rodovias 2014. Online, 2015. Disponível em < http://pesquisarodovias.cnt.org.br/>. Acesso em: 13 mar. 2015.

9. CNT. Confederação Nacional do Transporte. Pesquisa CNT de rodovias 2015. Online, 2015. Disponível em < http://pesquisarodovias.cnt.org.br/>. Acesso em: 6 nov. 2015.

10. DERANI, Cristiane. Privatização e serviços públicos: as ações do Estado na produção econômica. São Paulo: Max Limonad, 2002.

11. ECORODOVIAS. Apresenta informações sobre a EcoRodovias. Online, 2015. Disponível em: $<$ http://www.ecorodovias.com.br/>. Acesso em: 1 out. 2015.

12. EXAME. Lucro líquido da CCR no $4^{\circ}$ trimestre avança 25,37\%. Online 2015. 2015. Disponível em: <http://exame.abril.com.br/negocios/noticias/lucroliquidodaccrno4otrimestreavanca2537>. Acesso em: 6 mar. 2015.

13. HARVEY, David. Os limites do capital. São Paulo: Boitempo, 2013.

14. INVEPAR. Apresenta informações sobre a Invepar. Online, 2015. Disponível em: <http:// www.invepar.com.br/>. Acesso em: 15 set. 2015.

15. KURZ, Robert. A privatização do mundo. 2002. Disponível em: <http://resistir.info $>$. Acesso em: 26 mai. 2015.

16. LAZZARINI, Sérgio G. Capitalismo de laços: os donos do Brasil e suas conexões. Rio de Janeiro: Elsevier, 2011.

17. LEI Federal 8.987/95. Disponível em: <http://www.planalto.gov.br/ccivil_03/Leis/L8987cons. htm>. Acesso em: 15 jan. 2016.

18. LOGÍSTICA BRASIL. Apresenta informações sobre as concessões de rodovias no Brasil. Online, 2015. Disponível em: <http://www.logisticabrasil.gov.br/rodovias3>. Acesso em: 18 jun. 2015.

19. MANDEL, Ernest. O Capitalismo tardio. São Paulo: Nova Cultural, 1985.

20. MENTOR, Antonio; BITTENCOURT, Gerson. Voto em separado ao relatório final da CPI dos pedágios, apresentado pelos deputados Antonio Mentor e Gerson Bittencourt, da bancada do Partido dos Trabalhadores. São Paulo: 2014. Disponível em: <http://www.ptalesp.org.br/download/ noticia/Voto\%20separado\%20CPI\%20Pedagios\%202014.pdf>. Acesso em: 16 nov. 2014.

21. NEGRI, Barjas. Concentração e desconcentração industrial em São Paulo (1880 - 1990). Campinas: Unicamp, 1996.

22. ODEBRECHT TRANSPORT. Apresenta informações sobre o grupo Odebrecht TransPort. Online, 2015. Disponível em: <http://www.odebrecht-transport.com/pt-br >. Acesso em: 10 jul. 2015.

23. ODEBRECHT. Relatório anual - 2014. Online, 2105. Disponível em: <http://www.odebrechttransport.com/pt-br/empresa/relatorio-anual>. Acesso em: 21 out. 2015.

24. PEDRUZZI, Pedro; MELO, Melo. ANTT precisa de mais funcionários para fiscalizar rodovias concedidas. Online, 2015. Disponível em: $<$ ANTT precisa de mais funcionários para fiscalizar rodovias concedidasagenciabrasil.ebc.com.br/politica/noticia/2014-02/antt-precisa-de-maisfuncionarios-para-fiscalizar-rodovias-concedidas $>$. 
25. PUPO, Fábio. Atlantia e Bertin miram IPO, rodovias e aeroportos. Valor Econômico, 2013. Online, 2016. Disponível em: <http://www.valor.com.br/imprimir/noticia_impresso/3197714>. Acesso em: 11 Set. 2016.

26. RIZÉRIO, Lara. Governo Temer anuncia programa de concessões e privatizações de 25 projetos de infraestrutura; confira. Infomoney, 2016. Online 2016. Disponível em: <http://www. infomoney.com.br/mercados/politica/noticia/5532192/governo-temer-anuncia-programaconcessoes-privatizacoes-projetos-infraestrutura-confira>. Acesso em: 16 Set. 2016.

27. SANDRONI, Paulo. Novíssimo dicionário de economia. São Paulo: Editora Best Seller, 1999.

28. SANTOS, Leandro Bruno. Estado e internacionalização de empesas multilatinas [recurso eletrônico]. 1 Ed. São Paulo: Cultura Acadêmica, 2013.

29. SOSSELA, Gilmar (Relator). Relatório final. Assembleia Legislativa do Estado do Rio Grande do Sul. Comissão de Segurança e Serviços Públicos. Subcomissão de Pedágios. Porto Alegre, 2012.

30. SPOSITO, Eliseu Sposito; SANTOS, Leandro Bruno. Origem, consolidação e internacionalização do Grupo Camargo Corrêa. Revista Paranaense de Desenvolvimento, v. 2, p. 51-80, 2012.

31. TRIUNFO Participações e Investimentos. Apresenta informações sobre o grupo Triunfo Participações e investimentos. Online, 2015. Disponível em: <http://www.triunfo.com/>. Acesso em: 28 abr. 2015.

ARTIGO RECEBIDO EM SETEMBRO DE 2016

ARTIGO APROVADO EM FEVEREIRO DE 2017 